\title{
El devenir histórico de los paisajes culturales de un pueblo catamarqueño (Andalhuala, Yocavil, Argentina)
}

\section{The Historical Trajectory of Cultural Landscapes of a Catamarca Village (Andalhuala, Yocavil, Argentina)}

\author{
Alina Álvarez Larrain* \\ Universidad Nacional Autónoma de México
}

\begin{abstract}
RESUMEN
Este trabajo se propone realizar una síntesis del devenir histórico de los paisajes culturales de Andalhuala, un pueblo catamarqueño del noroeste argentino. Entendemos los paisajes culturales como construcciones sociales producto de la interacción de las personas con sus entornos. Abarcaremos desde los primeros grupos cazadores-recolectores que habitaron la zona hasta el periodo colonial, cuando se afianza la sociedad española. En el contexto actual de revalorización de las culturas ancestrales en Argentina, esperamos que el caso de estudio proporcione un mejor conocimiento de dicha herencia cultural para entender los procesos de cambio en el largo plazo de estos paisajes precolombinos, producto de distintos modos de habitar, episodios de conquista y configuración de nuevas identidades sociales.
\end{abstract}

Palabras clave: paisajes culturales, sociedades precolombinas, Andalhuala, noroeste argentino.

\begin{abstract}
$\overline{\text { ABSTRACT }}$
This work aims to synthesize the historical trajectory of the cultural landscapes of Andalhuala, a village located in Catamarca, Northwest Argentina. Cultural landscapes are understood as social constructs that are the product of the interaction of people with their environments. Temporally, we will cover from the first huntergatherer groups that inhabited the area until the Colonial period, when the Spanish society is consolidated. In the current revaluation of ancestral cultures in Argentina, we expect this case study to provide a better understanding of this cultural heritage and the long-term processes of change of these pre-Columbian landscapes resulting from different ways of inhabiting, episodes of conquest, and configuration of new social identities.
\end{abstract}

Keywords: cultural landscapes, pre-Columbian societies, Andalhuala, Argentine Northwest.

\footnotetext{
Doctora en Arqueología de la Universidad de Buenos Aires. Becaria posdoctoral DGAPA-UNAM en el Centro de Investigaciones en Geografía Ambiental, Universidad Nacional Autónoma de México, Campus Morelia; miembro del Conicet-Instituto de las Culturas (Idecu), Universidad de Buenos Aires (UBA). Recientemente publicó: "Paisajes agroalfareros del primer y segundo milenio DC en la Mesada de Andalhuala Banda (Yocavil, noroeste argentino)", Ñawpa Pacha: Journal of Andean Archaeology 36, n.o 2 (2016): 161-184 y "Don Mateo-El Cerro, a Newly Rediscovered Late Period Settlement in Yocavil (Catamarca, Argentina)", Andean Past 12 (2016): 203-210. alinaalvarez larrain@gmail.com.
} 


\section{Introducción}

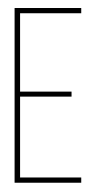

l noroeste argentino (en adelante NOA) es una región geográfica comprendida en el área andina meridional que limita con Bolivia y Chile. Su territorio abarca los ambientes desérticos del altiplano, los valles y quebradas que se despliegan hacia el sur y el este de la puna y la ceja de selva hacia el oriente. Las evidencias de ocupación humana en esta región se remontan hasta finales del Pleistoceno, con bandas de cazadores recolectores. Para el siglo XV, momento de la Conquista española, sociedades sedentarias productoras de alimentos ya modelaban los paisajes de la región (Albeck 2000; Aschero 2000; Castro y Tarragó 1992; Ruiz 1995-1996).

Los valles Calchaquíes del NOA (de los cuales el valle de Yocavil o Santa María es su porción sur) fueron una región de gran complejidad sociopolítica en tiempos prehispánicos y actualmente es una zona rica en vestigios arqueológicos (Scattolin 2010; Tarragó 2000; Williams 2003). Estos valles son significativos también dado que a la llegada de los españoles le siguió más de un siglo de rebeliones indígenas contra la dominación europea, una resistencia singular en el mundo andino que construyó una imagen de los indígenas de la región como indómitos y peligrosos (Rodríguez 2008, 2011).

En la década de 1960, los pobladores del valle de Yocavil parecían desconocer la suerte de las poblaciones nativas (Rodríguez y Lorandi 2005, 435), aunque numerosos sitios arqueológicos eran evidencia de su existencia pasada ${ }^{1}$. Según Rodríguez y Lorandi (2005), el legado precolombino no formaba parte de la autoidentidad cultural del área, que se percibía como de descendencia europea o a lo sumo mestiza. No obstante, para inicios del 2000 esa situación comenzó a cambiar con el surgimiento de una preocupación social y política por recuperar las tradiciones y el pasado prehispánico, poco conocido por los locales, pero revalorado como lo culturalmente "auténtico" (436). En este proceso se fueron constituyendo comunidades indígenas locales, vinculadas a través de la Unión de los Pueblos de la Nación Diaguita, que fueron recuperando, revalorizando y

1 Nos referimos, principalmente, a los poblados-pukara del periodo Tardío (1000-1430 d. C.) que albergaban a cientos de miles de habitantes y que aún hoy se destacan en el paisaje del valle. 
recreando prácticas culturales de reminiscencia prehispánica (Isla 2003; Lazzari y Korstanje 2013; Marchegiani et al. 2006).

En este contexto sociopolítico de revalorización de rasgos de las culturas ancestrales, y a partir de encuentros con pobladores, maestros y estudiantes de Andalhuala interesados en conocer el pasado precolombino de su pueblo, nuestro objetivo es hacer una síntesis del conocimiento existente hasta el presente sobre los paisajes culturales de Andalhuala que contribuya a un mejor entendimiento de dicha herencia cultural. El rango temporal abarcado va desde unos 10.000 años antes del presente (a. P.), con los primeros grupos cazadores-recolectores que habitaron la zona, hasta el siglo XVIII d. C., momento en el que se afianza la sociedad colonial española al tiempo que se produce un proceso de repoblamiento indígena en los valles.

Abordaremos el devenir histórico de Andalhuala poniendo el eje en el estudio de los paisajes culturales en el largo plazo. Entendemos los paisajes culturales como construcciones sociales que son el producto de la interacción de las personas con sus entornos (Criado 1999; Thiébaut, García y Jiménez 2008; Tilley 1994), donde cada grupo introduce sus propias pautas de ocupación, añadiendo estratos a los restos materiales de los usos anteriores (Anschuetz et al. 2001; Bailey 2007).

La manera en que la gente se relaciona con el mundo depende del tiempo, el lugar y las condiciones históricas específicas (Bender 1993); las formas del paisaje, sus lugares significativos, se construyen y cambian a partir de la temporalidad del movimiento de los seres humanos que lo habitan (Ingold 2000; Tilley 1994). Al moverse a través de los paisajes construidos, es decir, en espacialidades significativamente constituidas, las personas adquieren conocimiento sobre las cosas y sus relaciones (Bourdieu [1972] 2012). Así, un punto de partida en el estudio de los paisajes es el registro de los distintos lugares habitados y modificados por los seres humanos en sus actividades cotidianas e interacciones con el entorno. El estudio de dicha materialidad, entendida como la relación que se establece entre los sujetos y los objetos en las prácticas sociales que los constituyen mutuamente (Miller 2005), permite abordar los paisajes que fueron el producto de distintos modos de habitar de los grupos asentados allí (Ingold 2000). El concepto de lugar (Tuan [1977] 2003) se refiere a localidades que se vuelven significativas desde la experiencia humana, y pasan a formar parte de mundos más extensos de sentido y acción. La reconstrucción progresiva de la red de lugares en Andalhuala nos permite desagregar algunos de los distintos paisajes que se sucedieron en esta localidad (Smith 2003; Thomas 2001; Zedeño 2000). 
La revisión presentada aquí constituye una mirada amplia de la historia de la zona, basada en la recopilación de estudios antropológicos y etnohistóricos, investigaciones arqueológicas llevadas a cabo por el Proyecto Arqueológico Yocavil desde la década de los ochenta y mis propios trabajos de campo en Andalhuala durante mis estudios de licenciatura y doctorado. Los cortes temporales propuestos responden a hitos que marcaron la historia del valle, tal como fueron abordados en las investigaciones científicas. El caso es pertinente también para entender los procesos de cambio en el largo plazo que han sufrido los paisajes precolombinos del noroeste argentino, en relación con los distintos modos de habitar de las poblaciones nativas y foráneas, los episodios de conquista que han enfrentado y la consecuente configuración de nuevas identidades sociales.

\section{Marco geográfico}

El valle de Yocavil (provincias de Tucumán y Catamarca) es una depresión tectónica de $100 \mathrm{~km}$ de longitud, surcada por el río Santa María y enmarcada por la Sierra del Cajón o Quilmes al oeste, y por las Cumbres Calchaquíes-Sierra del Aconquija al este. Se caracteriza por ser un entorno semiárido, con precipitaciones estivales (O. Ruiz 1972). Actualmente, la población del valle se concentra en pueblos ubicados en un eje longitudinal a lo largo de la planicie aluvial del río Santa María (que coincide con el trayecto de la Ruta Nacional 40), y en caseríos sobre los valles y quebradas del este (figura 1).

La localidad de Andalhuala ${ }^{2}$ se ubica entre el río Santa María y la Sierra del Aconquija, a $25 \mathrm{~km}$ al sureste de la ciudad de Santa María y a $9 \mathrm{~km}$ de San José, capital del municipio homónimo al que pertenece. Desde Santa María se llega en vehículo tomando la ruta nacional 40 rumbo al sur unos $16 \mathrm{~km}$ y luego girando hacia el este por la ruta provincial 39 otros $8 \mathrm{~km}$, una vía sin pavimentar que desemboca en el centro cívico de Andalhuala (figura 2). Este nombre es un topónimo en lengua kakán ${ }^{3}$ que hablaban las poblaciones nativas del valle en tiempos prehispánicos. Con el arribo de los españoles que poseían algunos conocimientos del quechua adquiridos en Cusco, se fomentó este idioma foráneo

2 Muchas veces confundida con Andalgalá, en el departamento homónimo, aparece escrita también como "Andalhualá", "Andalgualá", "Andalguala" y "Andaguala".

3 La única referencia que tenemos sobre el significado del topónimo lo encontramos en Lafone Quevedo $(1898,28)$, quien propone que el nombre vendría de anta = cobre y huala = cosa redonda, haciendo alusión a "un bolón o disco colosal de arenisca roja". 
Figura 1. Mapa del valle de Yocavil con la ubicación de algunas ciudades modernas y poblados prehispánicos

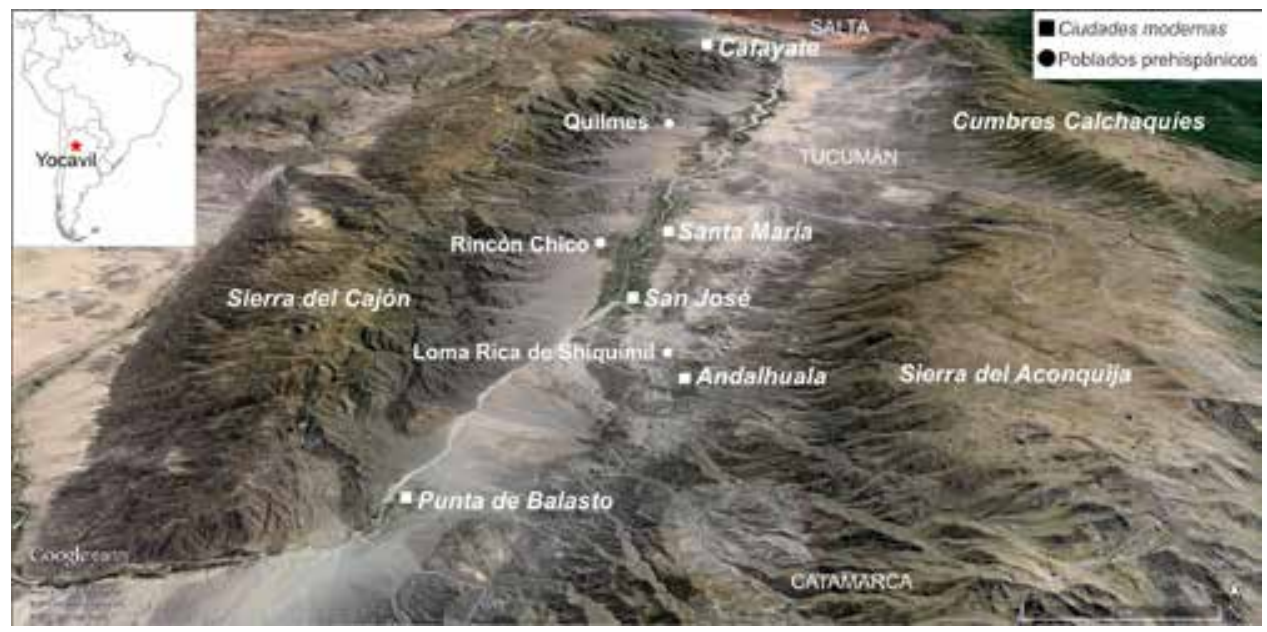

Fuente: imagen satelital tomada de Google Earth Pro 2014.

como lengua franca debido a la dificultad de aprender el kakán por sus sonidos guturales (Giudicelli 2013); como consecuencia, el kakán se ha convertido en una lengua muerta de la que solo sobreviven topónimos y apellidos.

La población actual de Andalhuala se encuentra sobre una formación sedimentaria del Terciario Superior (formación Andalhuala), que se adosa al basamento precámbrico de la Sierra del Aconquija (Ruiz Huidobro 1972). Sobre estos sedimentos se formaron depósitos aluviales del Cuaternario (formación Caspinchango), antiguos abanicos aluviales labrados por la erosión laminar y eólica que hoy se observan como glacis ${ }^{4}$. Este ambiente de mesadas se encuentra surcado por los principales cauces tributarios del río Santa María que nacen en la cumbre de la Sierra del Aconquija y generan un entorno de “oasis fértiles”, que contrasta con el ambiente más árido del valle principal (Tineo 2005) (figura 3)5.

Los lugareños denominan a los glacis mesadas, dadas sus extensas superficies planas y elevadas con respecto al entorno.

En las mesadas se encuentra representado el monte espinoso, arbustal abierto con especies caducifolias espinosas, y la estepa de Larrea (o de jarillas), junto con la presencia de cactáceas columnares (cardones) hacia el oriente. Este tipo de vegetación es utilizada como leña, para forraje de cabras, construcción de corrales y techos. De los bosques originarios de algarrobo, tan preciados por las poblaciones prehispánicas, solo se preservan pequeños sectores dado que la agricultura ha llevado a una tala extensiva. Los glacis altos y las faldas bajas de la Sierra del Aconquija, entre los 2.500-3.000 m s. n. m., se caracterizan por la presencia de la provincia Prepuneña con cactáceas columnares de gran tamaño, mientras que por encima de los 3.000 m s. n. m. se encuentra la provincia Puneña, con una vegetación baja y rala de estepa arbustiva abierta, y la provincia Altoandina, con estepa de gramíneas duras (Cabrera 1976). 
Figura 2. Imagen satelital de Andalhuala. Las estrellas indican sitios arqueológicos

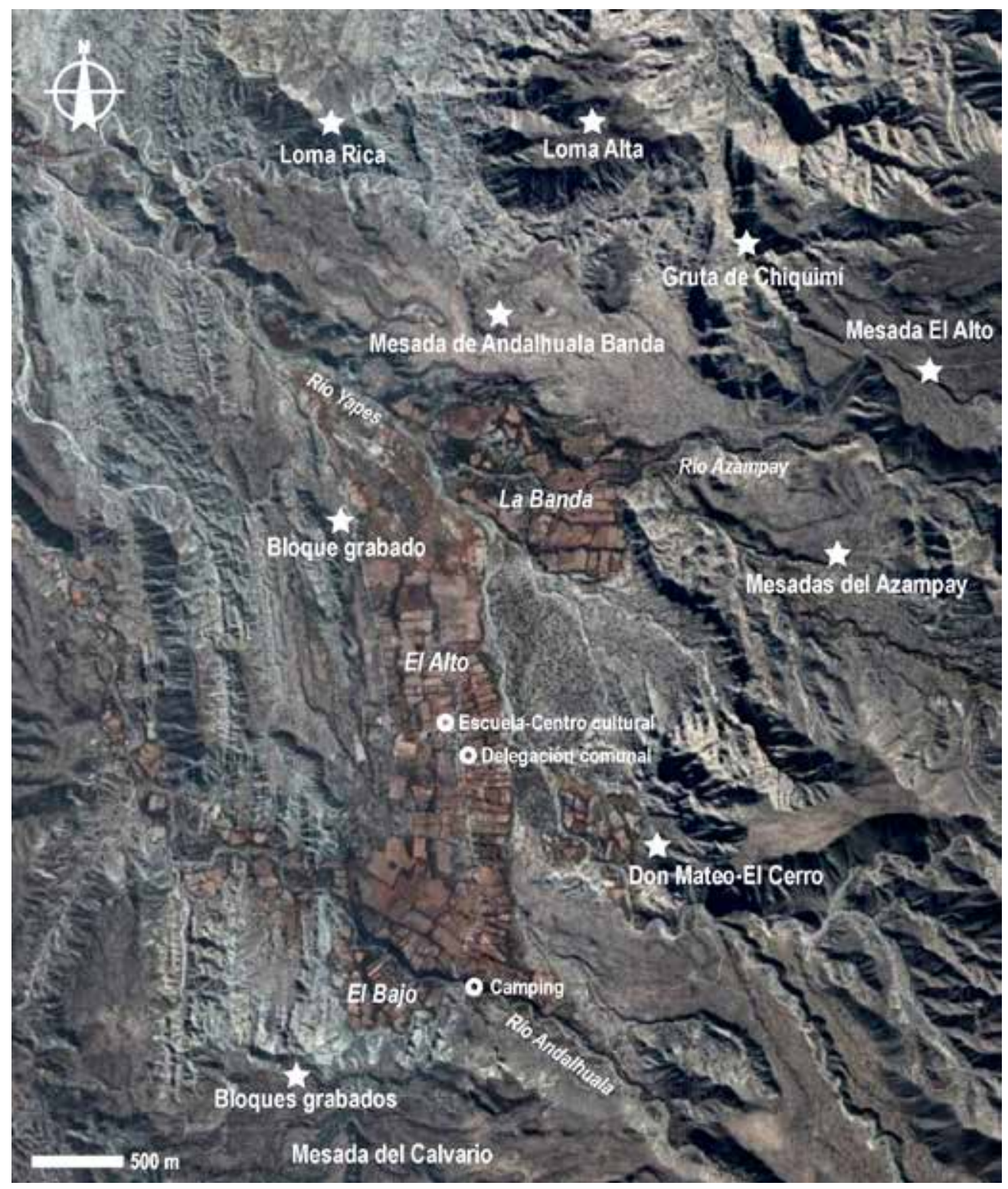

Fuente: imagen satelital tomada de Google Earth Pro 2014. 
Figura 3. a. Río Andalhuala; b. Río Azampay
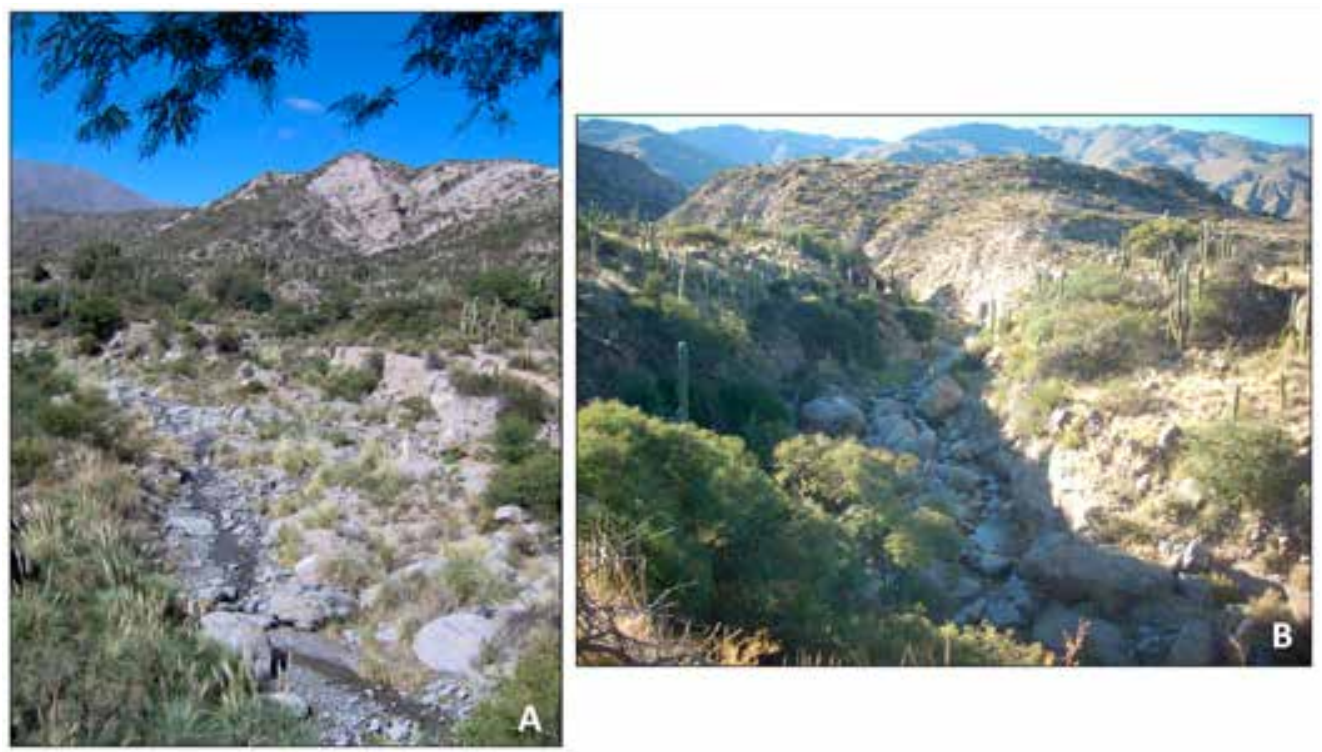

Fuente: elaboración propia.

En Andalhuala se distinguen tres sectores de caseríos con pequeñas fincas de propiedad privada que no suelen superar las 5 o 6 ha cada una. La economía del pueblo se centra en el cultivo de árboles frutales (nueces, duraznos, vid, membrillo), papa y ají, junto a la cría de ganado europeo (Bolsi 1967). El sector meridional es Andalhuala del Bajo, conformado por terrenos cultivados sobre la planicie aluvial del río Andalhuala, cerrados por el sur por una mesada alta donde se construyó un calvario o vía crucis. El sector central, Andalhuala del Alto, consiste en el trecho de planicie aluvial abandonada del antiguo curso del río Andalhuala, limitado al sur por el río Andalhuala y al norte por el río Yapes. En este sector se ubica el centro cívico del pueblo; allí las fachadas de las viviendas se ubican mirando al camino principal, sobre cuyo eje se encuentran también la escuela, el centro cultural, el destacamento policial, la delegación comunal, la iglesia y la posta médica. Al norte, Andalhuala La Banda consiste en fincas situadas en las planicies aluviales de los ríos Yapes y Azampay. Durante la época estival, la comunicación con las otras zonas se ve reducida debido a que la vía sin pavimentar que atraviesa ambos lechos queda anegada. En La Banda y El Bajo, si bien las viviendas se encuentran cerca de los caminos de acceso, presentan un patrón más disperso (figura 4). 
Figura 4. a. Vista de Andalhuala La Banda desde el norte; b. vista de Andalhuala del Alto desde el sur; c. calle principal del Alto; d. vista de Andalhuala del Bajo desde el este
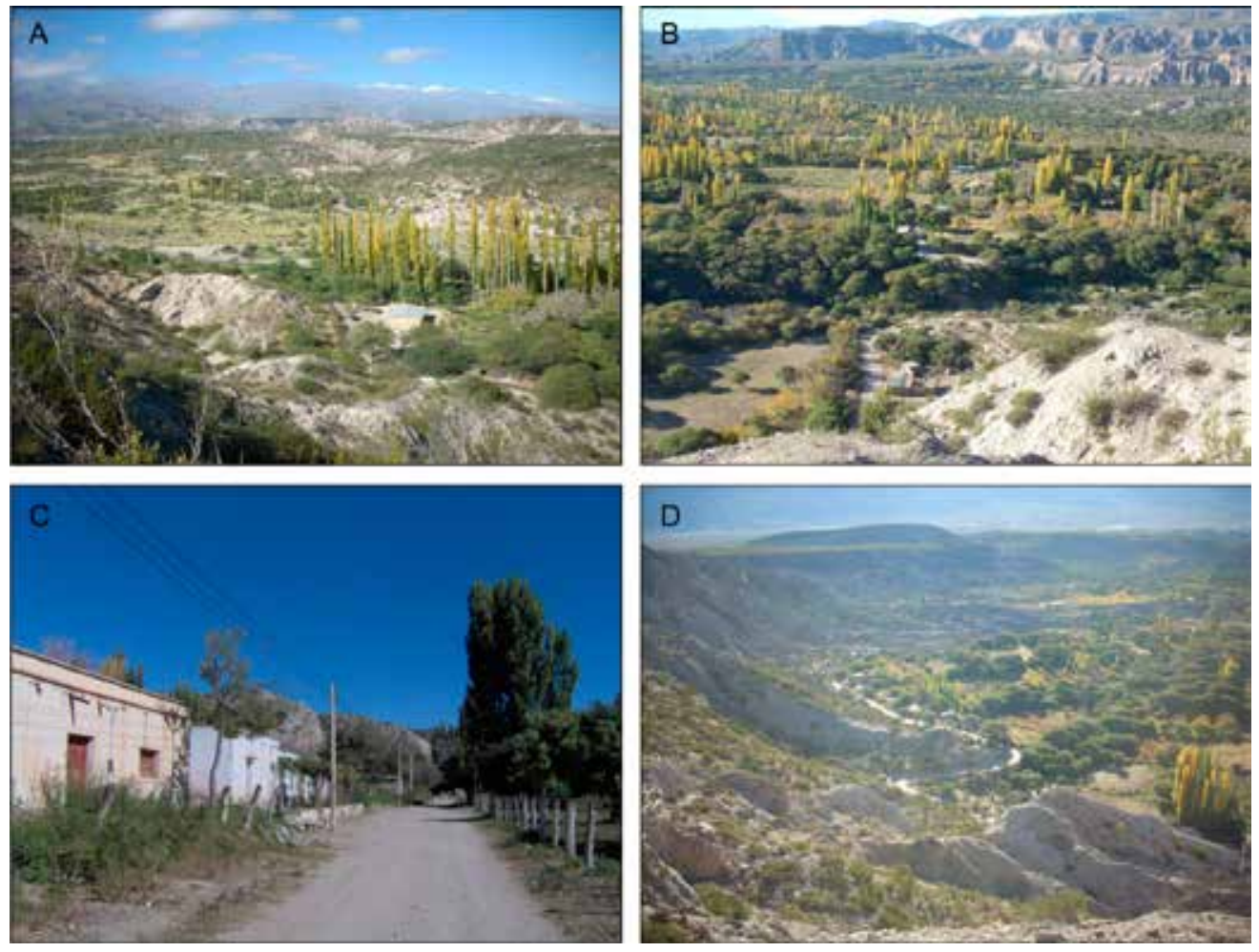

Fuente: elaboración propia.

\section{El paisaje de los cazadores-recolectores (10.000 años antes del Presente)}

Hace unos 10.000 a 8000 años a. P., el valle de Yocavil estuvo poblado por grupos cazadores recolectores (CR). Se sabe poco de estos primeros pobladores, dado que sus asentamientos son difíciles de hallar, por un lado, porque eran cuevas y aleros internados en la sierra o porque contaban con construcciones temporales que no se habían preservado y, por otro lado, debido a la larga trayectoria de ocupación que ha generado un palimpsesto o superposición de paisajes, que ha borrado o alterado las huellas de estas ocupaciones más antiguas.

Un pionero en el estudio de estas poblaciones en Yocavil fue Eduardo Cigliano, quien trabajó en un sitio cantera-taller emplazado en una hoyada rodeada 
de mesadas en la localidad de Ampajango, al sur de Andalhuala (Cigliano et al. 1962). Allí, definió la llamada Industria Ampajanguense, compuesta por grandes lascas, bifaces, raederas y raspadores confeccionados sobre andesita, materia prima de fácil acceso y buena calidad que predomina en forma de grandes bloques en la superficie de mesadas y vallecitos (figura 5a).

Figura 5. a. Punta Ampajanguense (adaptado de Cigliano et al. 1962, figura 59); b. puntas Ayampitín (adaptado de González 1952, lámina 13). Originales sin escala

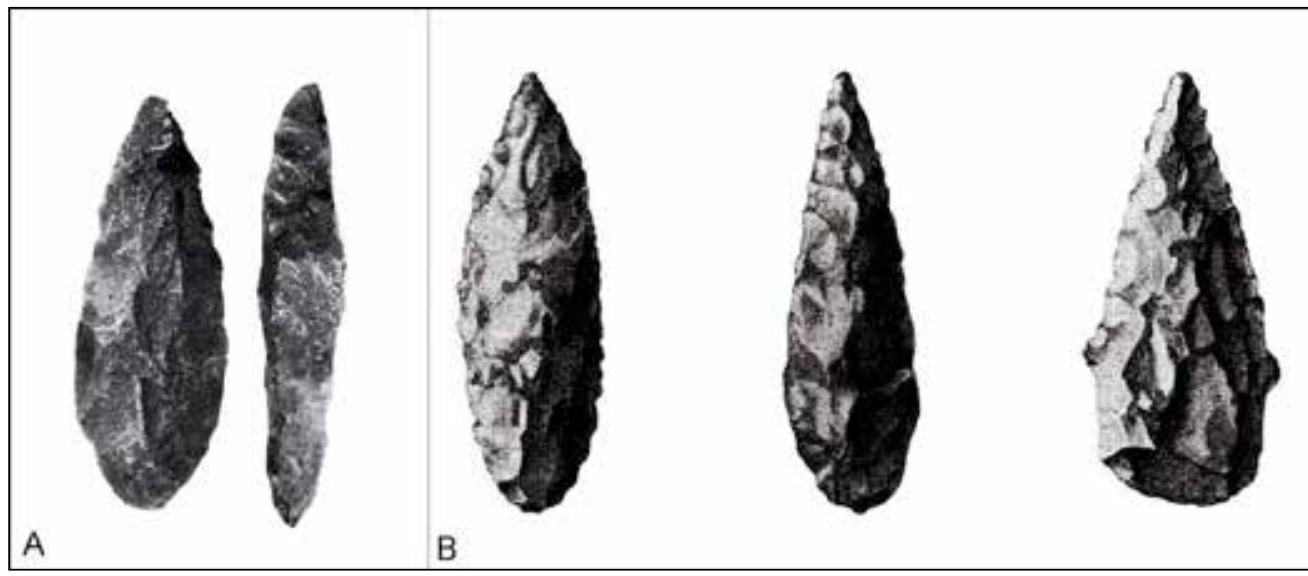

Fuente: elaboración propia.

Esta línea de investigación ha sido retomada por Juan Pablo Carbonelli (2013a, 2013b), en localidades del sudeste del valle como Andalhuala, donde también se han hallado materiales de la Industria Ampajanguense. Sus trabajos han permitido determinar que otra de las rocas de buena calidad utilizada por estas poblaciones fue el basalto, disponible en forma de nódulos sobre las mesadas o rodados transportados por los ríos. También se ha encontrado cuarzo, materia prima disponible de menos calidad para la talla, pues su dureza hace difícil predecir el tipo de lasca que se obtendrá.

Carbonelli (2013b) ha propuesto que el sitio cantera-taller de Ampajango pudo ser utilizado durante miles de años para obtener preformas de instrumentos y bifaces, luego empleados o retrabajados en otros sitios de las cercanías, como Andalhuala. Las prospecciones en la zona no han permitido encontrar aún sitios como puestos de caza, campamentos residenciales, escondrijos o campamentos logísticos, con la excepción de estructuras rústicas consideradas parapetos en la mesada del Calvario (Myriam N. Tarragó, comunicación personal).

Cigliano describió también la existencia de puntas Ayampitín en las mesadas que rodean la cantera-taller de Ampajango. La Industria Ayampitín fue 
definida en las Sierras Centrales de Córdoba por Alberto R. González (1960), a partir de la presencia de grandes puntas de proyectil lanceoladas (con forma de hoja de laurel), trabajadas en ambas caras por retoque a presión (figura 5b). Estas puntas se integraban como cabezal a un astil que facilitaba la propulsión, conformando un arma arrojadiza o de enfrentamiento a corta distancia, óptima para la caza de guanacos (Lama guanicoe). Esta tecnología lítica cuenta con una amplia dispersión en el NOA y una antigüedad de unos 8000 años a. P. (Bonnin y Laguens 2000).

Un material lítico de superficie procedente de la Mesada de Andalhuala Banda arrojó datos interesantes que complejizan la ocupación de Andalhuala durante épocas tan tempranas. A partir de la comparación de atributos morfológicos de puntas de flechas halladas allí con tipos morfológicos definidos para sitios fechados de Antofagasta de la Sierra, Carbonelli (2013a) ha podido utilizar los diseños de algunas puntas como marcadores cronológicos. Una punta de proyectil con pedúnculo, elaborada en andesita, presenta similitud con un grupo morfológico de armas arrojadizas datado en 5490-4350 a. P. Otra punta con pedúnculo y aletas en espolón de andesita se asemeja a un grupo morfológico de 4150-3430 a. P., siendo un arma arrojadiza de corto alcance. Asimismo, dos bifaces tallados en andesita se encuentran asociados a las actividades de talla de grupos CR, técnica que no se registra en las sociedades agropastoriles de la zona (Carbonelli 2011). Estas semejanzas han llevado a Carbonelli a plantear a la Mesada de Andalhuala Banda como un paisaje utilizado desde por lo menos 5000 años a. P. como lugar de caza o tránsito dentro de los trayectos recorridos hacia las faldas del Aconquija para dicha actividad.

Una nueva vía de análisis en desarrollo para el estudio de los grupos CR es la datación de la microestratigrafía del barniz del desierto, una pátina cobriza presente en la superficie de los bloques y artefactos cuya formación se encuentra afectada por variaciones climáticas en regiones áridas (Somonte 2009). Una datación de este tipo sobre dos lascas de andesita recuperadas en Ampajango dio como resultado que la capa más antigua de barniz fue depositada hace 9400 años a. P., siendo la manufactura del artefacto lítico anterior a esa fecha lo que demuestra la profundidad temporal de la ocupación humana en el área (Carbonelli 2013a). 


\section{La aldea como centro del espacio habitado (primer milenio d. C.)}

Hace unos 3000 años a. P. se consolidó en el NOA un modo de vida sedentario en el que se combinaron la caza y recolección con la agricultura y el pastoreo (Olivera 2001; Tarragó 1999). El paisaje estaba habitado por pequeñas comunidades asentadas en aldeas con arquitectura residencial y agrícola, lugares y recipientes de almacenaje y vasijas cerámicas para la cocción de alimentos. Los asentamientos presentaban un patrón disperso, en el que cada vivienda estaba rodeada de sus campos de cultivo, o bien, con un núcleo habitacional más concentrado próximo a las áreas agrícolas (Scattolin 2010). La vivienda predominante fue la de planta circular, conocida como patrón alveolar o tipo Tafí. El recinto central de mayores dimensiones era el patio donde la familia realizaba actividades como el procesamiento de materias primas y la elaboración de manufacturas, cocción y almacenamiento de alimentos, entierro y culto a los muertos (Berberián y Nielsen 1988).

En Yocavil, reconstruir ese mundo agroalfarero temprano no es fácil. Al igual que pasa con los $\mathrm{CR}$, la magnitud de las ocupaciones más tardías ha alterado las evidencias de estas poblaciones, de las cuales, sin embargo, se conocía una importante cantidad de piezas arqueológicas en museos nacionales y extranjeros (Scattolin 2000). En comparación con la cantidad de poblados tardíos registrados en los valles Calchaquíes, las pruebas de asentamientos del primer milenio d. C. son pocas (Tarragó y Scattolin 1999); en este sentido, Andalhuala se ha configurado como un lugar central para la investigación de esas primeras poblaciones sedentarias de Yocavil. Trabajos de excavación emprendidos desde el año 2002 en la Mesada de Andalhuala Banda permitieron conocer diversos aspectos de la casa más antigua encontrada en el valle (Palamarczuk et al. 2007), sitio que fuera llamado Soria 2 por el nombre de la familia Soria de La Banda, que brindó albergue al equipo de trabajo del Proyecto Arqueológico Yocavil en sucesivas temporadas de campo. Por otro lado, el conjunto artefactual de Soria 2 ha permitido esbozar un periodo Temprano con rasgos locales que se diferencian ligeramente de las culturas arqueológicas definidas en otras áreas del NOA (González 1977).

Soria 2 es una casa conformada por, al menos, dos habitaciones adosadas de plantas cuadrangulares con esquinas redondeadas, denominadas recintos $1 \mathrm{y}$ 2 (figura 6). Sus muros de piedra eran solo parcialmente visibles en la superficie antes de las excavaciones, dadas las alteraciones producidas por las ocupaciones tardías de carácter habitacional y agrícola. Fueron construidos con piedras seleccionadas de tamaño uniforme, ubicando las caras planas hacia el interior de los 
espacios habitados. Es factible que los muros se continuaran hacia arriba con paredes de adobes, tapia o algún otro material perecedero que hoy no se conserva.

Figura 6. Recintos 1 y 2 de Soria 2

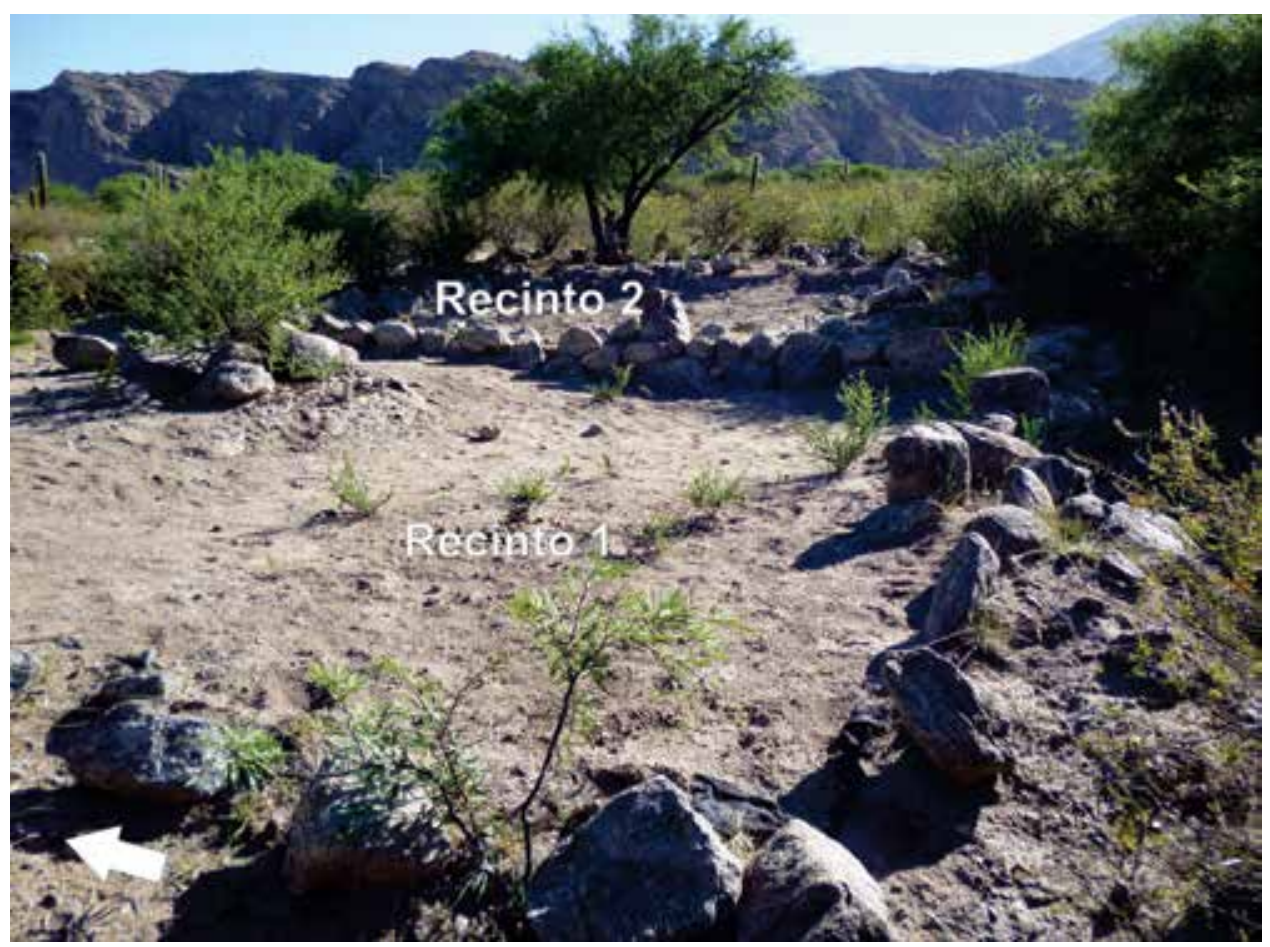

Fuente: elaboración propia.

El Recinto 1, de unos $8 \mathrm{~m}$ de lado, ha sido interpretado como un patio. A partir de la presencia de un fogón, agujeros de postes, un pozo de residuos, la posición horizontal de los hallazgos, restos de animales (camélidos, armadillos y cérvidos), restos vegetales (quínoa: Chenopodium quinoa, algarrobo: Prosopis, maíz: Zea mays y chañar: Geoffroea decorticans) y el ensamble de los fragmentos cerámicos, se pudo determinar la presencia de una superficie de ocupación donde los habitantes de Soria llevaron a cabo actividades como la cocción y el consumo de alimentos.

El conjunto cerámico “ordinario” de cocción oxidante, pasta gruesa y superficies alisadas responde en su mayoría a ollas empleadas para la cocción y tal vez para el almacenaje. El conjunto "fino”, de pastas delgadas plomizas y superficies pulidas, está representado en su mayoría por pucos (cuencos). Algunos poseen modelados zoomorfos aplicados sobre los labios. Ambos tipos de alfarerías 
fueron utilizados tanto en el ámbito cotidiano, en tareas de consumo y servicio de alimentos y bebidas, como en eventos excepcionales para el entierro de niños dentro de los muros de la casa (Baigorria di Scala 2009; Spano, Grimoldi y Palamarczuk 2014). También, fue hallado aquí un fragmento de pipa cerámica, artefacto que las sociedades tempranas utilizaban para fumar cebil (Anadenanthera colubrina) y otras plantas psicoactivas en contextos rituales (Rosso y Spano 20052006) (figura 7).

Figura 7. Hallazgos de Soria 2. a. Puco no restringido bruñido; b. botellón negro pulido con decoración incisa; c. botellón con decoración modelada e incisa (adaptado de Spano 2008; figs. 29, 30a y 49a);

d. cuchillo con retoque bifacial marginal de filita; e. puntas de proyectil de obsidiana (adaptado de Carbonelli 2013; figs. 2 y 3 )

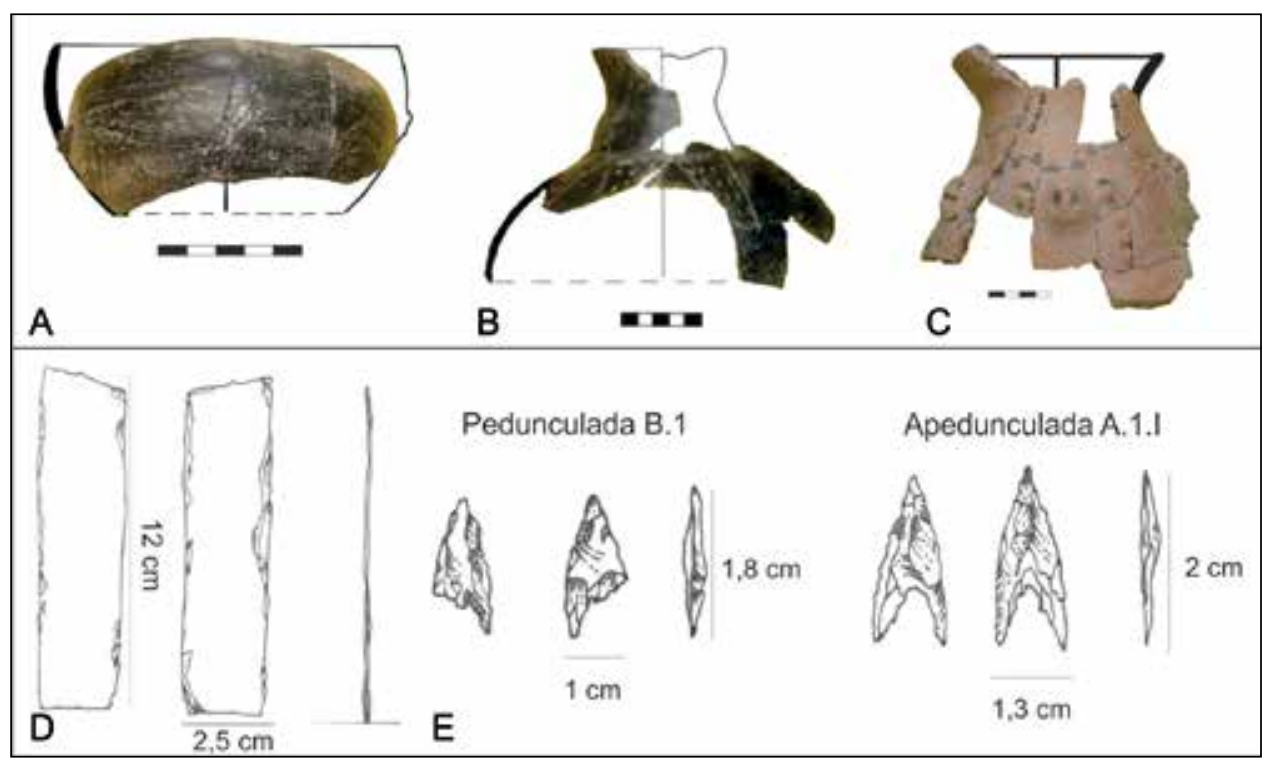

Fuente: elaboración propia.

El conjunto lítico de Soria 2 fue confeccionado principalmente en andesita, materia prima local. La excepción más destacada son dos puntas de proyectil de obsidiana, materia prima de excelente calidad para la talla, proveniente de las fuentes Ona y Laguna Cavi ubicadas en Antofagasta de la Sierra, que indican el contacto de las sociedades tempranas de Andalhuala con sus contemporáneas de la puna (Carbonelli 2011). Para la preparación de los artefactos de molienda como molinos ${ }^{6}$, morteros y manos fueron seleccionadas rocas metamórficas, dados sus 
atributos de dureza, rugosidad, tenacidad y capacidad de abrasión (Carbonelli 2013a).

El Recinto 2 pudo tratarse de una habitación techada de $6 \mathrm{~m}$ de lado y su conjunto artefactual fue similar al encontrado en el R1. En ambas habitaciones se encontraron estructuras funerarias consistentes en vasijas y cerramientos de piedras empleados para el entierro de infantes. El análisis emprendido por Spano, Grimoldi y Palamarczuk (2014) señala que los eventos de entierro ocurrieron tal vez unos 200 años después del abandono de los recintos como espacio de vivienda, por gente que compartía pautas culturales con los habitantes, debido a las similitudes entre los recipientes cerámicos empleados en ambos contextos.

Los trabajos posteriores de registro de la arquitectura de superficie de la Mesada de Andalhuala Banda nos permitieron registrar otras 12 unidades arquitectónicas con recintos de plantas circulares y subcirculares con muros semejantes a Soria 2 (Álvarez 2016b). Un sondeo exploratorio (1 x $1 \mathrm{~m}$ ) de una de esas unidades, un recinto semicircular de 4 × $7 \mathrm{~m}$ de planta interna ubicada $300 \mathrm{~m}$ al NO de Soria 2, permitió descubrir, dentro de sus muros, la inhumación de un neonato en una olla de tipo ordinario, de forma restringida y cocción oxidante, semejante a las empleadas en Soria 2 (Álvarez, Spano y Grimoldi, en prensa). El análisis estratigráfico y artefactual de Soria 3, como optamos por llamar a la unidad arquitectónica 11, nos llevó a pensar que esta consistió en una antigua casa, utilizada como espacio funerario luego de su desocupación como espacio doméstico. Los fechados realizados sobre el individuo inhumado confirmaron la cronología temprana del entierro. Al mismo tiempo, los materiales cerámicos, líticos y restos faunísticos recuperados en el sondeo eran coherentes con un posible uso doméstico previo de la unidad (Álvarez, Spano y Grimoldi, en prensa).

Las prospecciones emprendidas en Andalhuala nos permitieron registrar arquitectura y estilos alfareros de modalidad semejante a Soria 2 y 3, en la margen sur del río Azampay. Estos espacios, próximos al río, parecen estar formando parte de un mismo sector de asentamiento donde se concentró la ocupación durante el primer milenio d. C. en Andalhuala. Una ocupación temprana en estos glacis bajos es esperable dadas las mejores condiciones en términos de calidad de suelos, pendiente moderada, insolación para los cultivos y accesibilidad al agua de riego. La ausencia de presión demográfica habría permitido la utilización de las mejores tierras para el cultivo, que requieren una inversión tecnológica moderada para su aprovechamiento. Aunque no tenemos datos directos, los campos de cultivo pudieron estar dispersos en íntima asociación con los recintos habitacionales, o bien, ubicados en los terrenos bajos del fondo de valle, donde hoy se concentra el pueblo. 
Por lo que conocemos hasta el momento, el periodo Temprano en Andalhuala se asemejaría a lo propuesto para las primeras aldeas registradas en el NOA que, no obstante, han tenido sus particularidades según las distintas regiones (Korstanje et al. 2015): sociedades sedentarias que subsistían principalmente de la agricultura y el pastoreo, enterraban a sus muertos y habitaban el paisaje a partir de patrones aldeanos dispersos o concentrados, pero con baja densidad demográfica y bajo nivel de diferenciación social, regidas, tal vez, por distinciones sexuales, grupos de edad y pertenencia a linajes.

\section{Pukaras, chacras y puestos en el paisaje "calchaquí" (1000-1430 d. C.)}

No sabemos aún si las poblaciones que habitaron Andalhuala durante el primer milenio d. C. fueron antepasados directos de las poblaciones tardías. La abundante presencia de alfarería San José, considerada de inicios del periodo Tardío (Palamarczuk, Álvarez y Grimoldi 2014; Podestá y Perrotta 1973), es un dato a favor de que la ocupación de la zona haya podido ser relativamente continua. De la gran cantidad de piezas del universo San José procedentes de entierros y conservada en museos, varios ejemplares son originarios de Andalhuala; incluso Ambrosetti (1899) denominó estas alfarerías con ese nombre. Estas se encuentran presentes de manera profusa en superficie y contextos estratigráficos de sitios arqueológicos de la localidad, como Loma Rica de Shiquimil y Mesada de Andalhuala Banda (figura 8).

Entre el 1000 y el 1430 d. C., las sociedades de los Andes meridionales habitaron un paisaje político marcado por el crecimiento y la redistribución poblacional, el conflicto armado y cambios climáticos (Arkush 2011; Bouysse-Cassagne y Harris 1987; Nielsen 2001, 2009). Las evidencias arqueológicas parecen indicar que para fines del 1200 d. C., cuando las sequías se volvieron más severas, el conflicto se incrementó, antes de que la región quedara bajo control del incanato (Arkush y Stanish 2005; Nielsen 2009). Algunos pukaras ${ }^{7}$ funcionaron como fortalezas en sentido estricto, es decir, refugios temporales para la congregación

$7 \quad$ Pukara (en lenguas quechua y aymara) o pucará (Diccionario de la lengua española, Real Academia Española) remite originalmente a las fortalezas de piedra construidas por las poblaciones indígenas de los Andes en lugares estratégicos elevados. Actualmente, el término también se emplea en arqueología para hacer alusión a poblados de ocupación permanente con características defensivas. 
Figura 8. Alfarerías San José procedentes de Andalhuala: a) pieza 44-1889 (colección Breyer depositada en el Museo Etnográfico J. B. Ambrosetti, FFyL-UBA); b) pieza MLP-Ar-(v) 5633 (Colección Methfessel, depositada en la División Arqueología del Museo de La Plata); c ) pieza MLP-Ar-(v) 4770 (Colección Lafone Quevedo, depositada en la División Arqueología del Museo de La Plata)

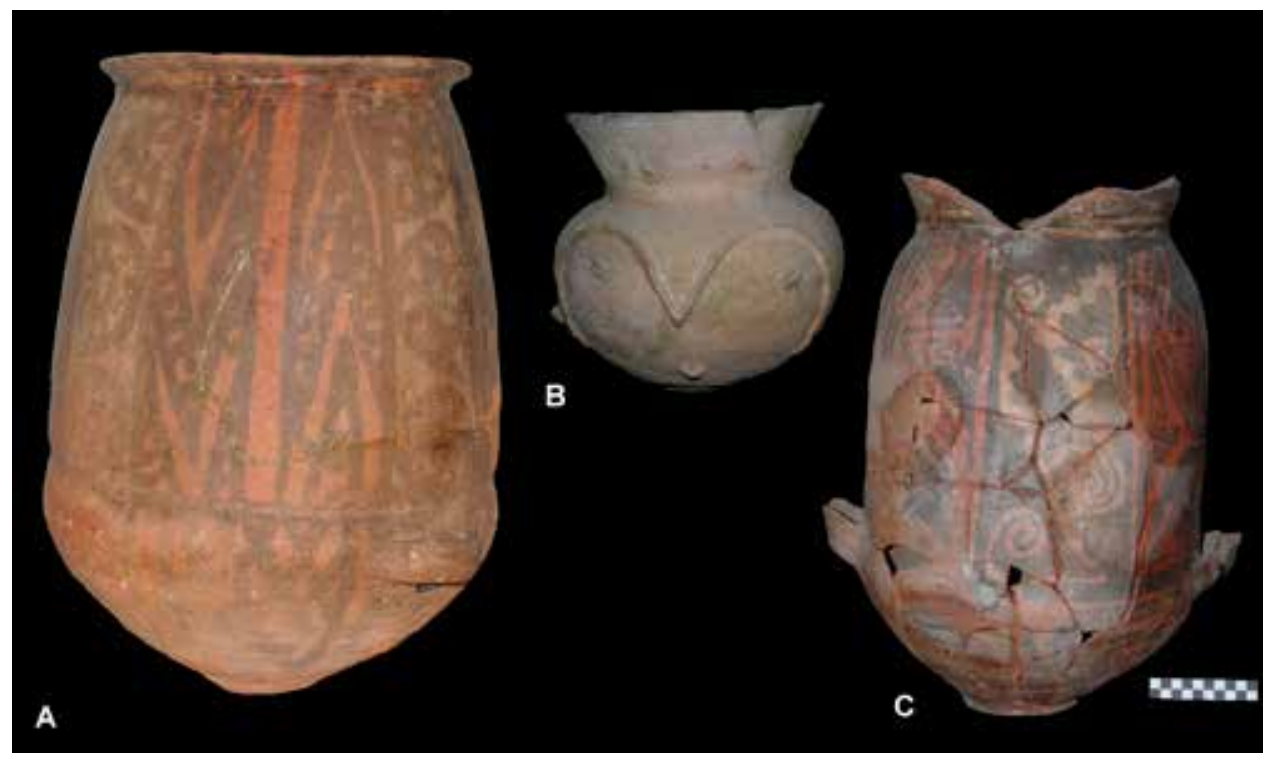

Fuente: elaboración propia, fotografías de Valeria Palamarczuk.

en momentos de amenazas (Arkush 2011; González Dubox et al. 2011), mientras que, un número elevado de ellos muestra evidencias de residencia permanente (Arkush 2011; Tarragó 2011; Uribe, Adán y Agüero 2004; Wynveldt 2009).

Las sociedades tardías del NOA formaron parte de este proceso surandino, caracterizadas por un cambio en los patrones de asentamiento con el surgimiento de poblados concentrados, extensas áreas agrícolas con regadío artificial y formas de cultura material regionalmente distintivas, como la Santamariana, con epicentro en Yocavil (Albeck 2000; Nielsen 2001, 2007; Tarragó 2000, 2011; Williams 2003). Este estilo se plasmó en distintos soportes (metalurgia, textiles, arte rupestre), pero es más conocido por la cantidad de tinajas y pucos (cuencos) empleados como urnas funerarias.

Alrededor del siglo XIII, centros poblados de cientos a miles de habitantes ubicados en la parte cumbral de cerros o sobre lomas elevadas se encontraban en funcionamiento, siendo considerados cabeceras políticas en la jerarquía de asentamientos y constituyendo un rasgo sustantivo de los paisajes tardíos (Tarragó 2011). En los valles Calchaquí y Yocavil se han registrado decenas de poblados con estas características. 
Por esta época, los valles Calchaquíes estaban habitados por distintos pueblos que compartían pautas culturales pero contaban con autonomía política, y fluctuaban entre encuentros bélicos y alianzas. Ellos se llamaban a sí mismos con distintos nombres: pulares, gualfines, angastacos, cafayates, tolombones, colalaos, amaichas, acalianes, quilmes, yocaviles, ingamanas, abaucanes, andalgalás, famatinas, entre otros (Lorandi y Boixadós 1987-1988), que hoy identifican varios de los lugares de la región. Producto de dos episodios de conquista que veremos en la próxima sección, pasaron a la historia como diaguitas - nombre que se cree fue dado por los incas - o calchaquíes — nombre que les brindaran los españoles por el apellido de un importante cacique-(Rodríguez 2011).

Según estudios etnohistóricos (Lorandi y Boixadós 1987-1988; Lorandi et al. 1997), los yocaviles poblaron la región sur-sudeste del valle, incluido probablemente el territorio de Andalhuala. Los estudios arqueológicos indican que la ocupación tardía de Andalhuala fue intensa (Álvarez 2010, 2015) y, posiblemente, el centro geográfico de un poderío político con base en Loma Rica de Shiquimil (Tarragó 2011; Tarragó et al. 1988). Este pukara cuenta con 189 recintos y 2 plazas en 2,45 ha de superficie cumbral, sobre un relicto de glacis que se levanta $100 \mathrm{~m}$ sobre el nivel del valle. Su emplazamiento hace su ascenso arriesgado y permite un dominio visual del valle troncal. Según Tarragó (2000), el pukara como centro social, político y religioso, circunscrito y elevado, ejercía un control del espacio agropecuario circundante que se extendía en los terrenos bajos.

Trabajos emprendidos en la Mesada de Andalhuala Banda, ubicada al pie del mencionado pukara, indicaron que gran parte de las unidades arquitectónicas registradas pudieron ser chacras, es decir, contaban con un uso agrícola durante este periodo (Álvarez 2015, 2016b). Las terrazas y recintos de siembra debieron ser empleados para el cultivo de maíz y otros cultivos mesotérmicos, como zapallo y ají. Montículos y acumulaciones longitudinales de piedras fueron el producto de tareas de despedre de la superficie para la siembra. Asimismo, estos campos debieron estar irrigados, como nos indican los tramos empedrados de canales y acequias. La presencia de morteros fijos, móviles y molinos revela que el procesamiento de alimentos fue realizado in situ. Estos debieron ser empleados tanto para el procesamiento de los granos del maíz como para las vainas de algarroba y frutos de chañar, plantas silvestres utilizadas desde épocas prehispánicas en la producción de harinas, arropes ${ }^{8}$ y bebidas fermentadas. Más de 60 unidades circulares de menos de $3 \mathrm{~m}$ de diámetro pudieron funcionar como depósitos. 
Dispersos entre las estructuras agrícolas se observaron recintos habitacionales de clara manufactura tardía. Estas unidades son interpretadas como lugares de residencia de las personas dedicadas a cultivar los campos, criar animales, procesar los alimentos y administrar los depósitos. No descartamos que algunas unidades simples de mayor tamaño fueran corrales empleados para el confinamiento de los camélidos en situaciones específicas ( $v$. gr. protección de llamas hembras y crías durante la época de parición, castración de machos, esquila o faena) (Flores 1977; Yacobaccio y Vilá 2012).

Las grandes áreas productivas del periodo Tardío, separadas de los poblados concentrados, indican sociedades de mayor tamaño que las comunidades aldeanas del primer milenio d. C. La asociación espacial en Andalhuala entre la mesada y el pukara es un buen indicador de que la población instalada en el bajo debió de ser la encargada de producir los alimentos para los habitantes que residían en el poblado alto, carente de espacios productivos básicos.

Otro poblado tardío se levanta al este de las fincas de Andalhuala del Alto. Denominado El Cerro por Arocena y Carnevali — quienes lo excavaron en 1960 - los lugareños lo conocen como Don Mateo o El Rincón (Álvarez 2016a). Ubicado sobre una pequeña falda de un glacis, cuenta con al menos 12 unidades arquitectónicas, entre ellas conjuntos de recintos adosados de muros dobles con relleno que se escalonan siguiendo la pendiente del cerro entre 2.280 y 2.323 m s. n. m. Es factible que el sitio comprenda un número mayor de recintos que abarcan un área aproximada de 26 ha, hoy cubierto por abundante vegetación. Este poblado pudo estar ligado a Loma Rica de Shiquimil, tanto en términos culturales, al mostrar una modalidad arquitectónica y estilos alfareros semejantes, como perceptivos, al presentar una excelente intervisibilidad entre las cumbres de ambos asentamientos, hipótesis que deberá ser contrastada con nuevos fechados radiocarbónicos para demostrar la estricta contemporaneidad de los asentamientos (figura 9). De ser demostrada dicha contemporaneidad, pensamos que la población de Loma Rica pudo aprovechar una localización topográfica estratégica que le otorgaba protección y control visual del valle principal, a la vez que le permitía proteger a la población rural y áreas agrícolas, como la Mesada de Andalhuala Banda, así como a poblados de fácil acceso, como Don Mateo.

Este fenómeno de disputa por recursos que caracterizó al periodo Tardío (Tarragó 2000; Williams y Castellanos 2011) podría explicar, asimismo, la presencia en Andalhuala de puestos de observación ubicados en los glacis altos, por encima de los 2.300 m s. n. m., lugares estratégicos del paisaje con control visual del espacio circundante. Uno de esos puestos fue la Loma Alta de Shiquimil, cerro que tiene muros de contención de ladera y recintos alineados sobre su flanco 
Figura 9. Vista de MAB y Don Mateo-El Cerro desde la cima de LRS

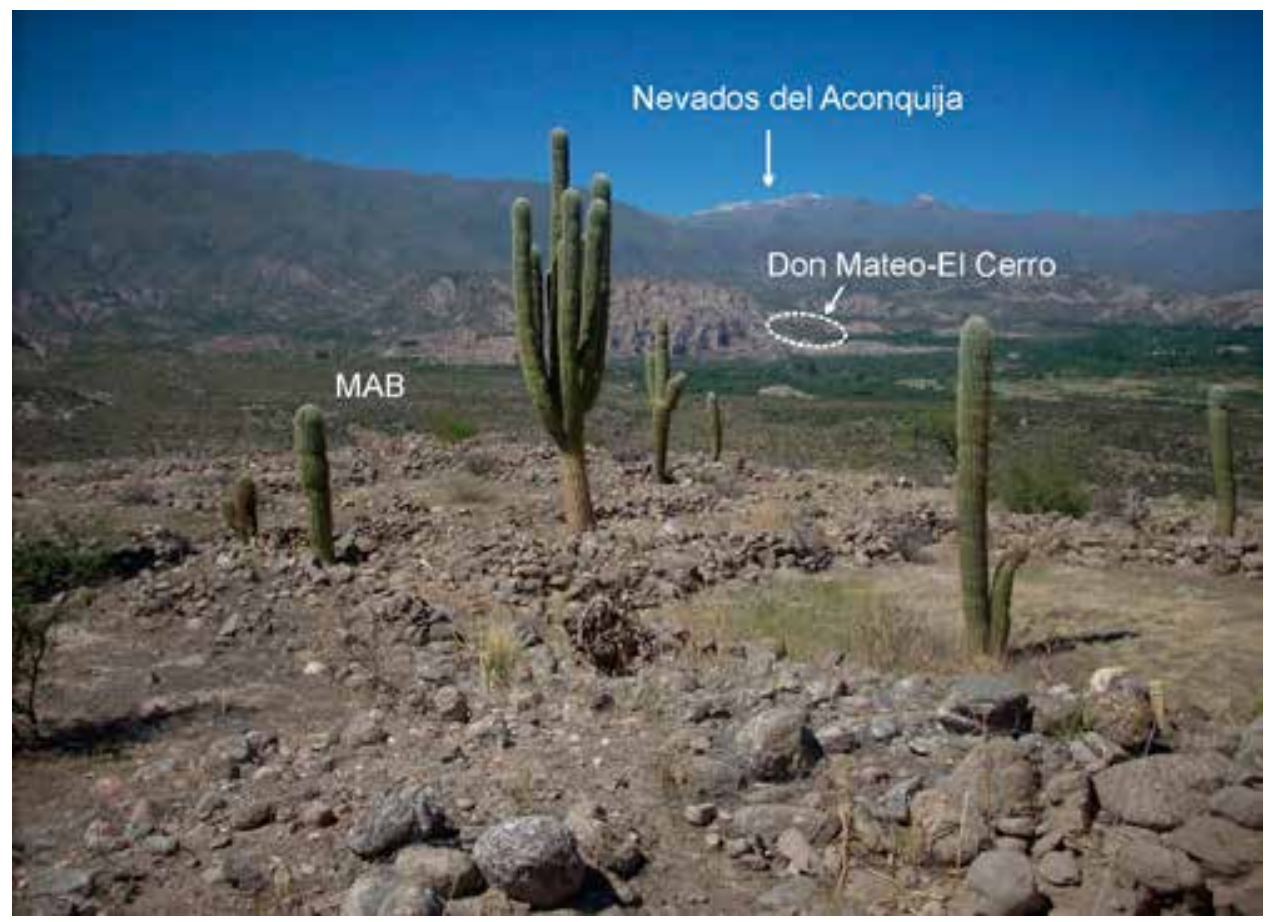

Fuente: elaboración propia.

oriental, empleados como puestos de observación del Camino de la Quebrada, paso natural entre las areniscas que conecta la población de Entre Ríos/Shiquimil con la Mesada de Andalhuala Banda. Un segundo puesto estuvo emplazado en lo que hemos denominado Alto de Andalhuala, con vista a Loma Rica y la Mesada de Andalhuala Banda. Debemos mencionar también estructuras registradas en la cima de Don Mateo, cuyo emplazamiento pudo relacionarse con el control visual del poblado bajo y terrenos productivos adyacentes. En este sentido, es interesante resaltar que estos puestos conforman una línea de buena intervisibilidad con el pukara, lo que sugiere la necesidad de un control coordinado del entorno ligado a la protección de los sectores bajos más vulnerables.

En íntima relación con el uso del espacio de las poblaciones tardías que ocuparon Andalhuala, debemos hablar también de las evidencias de arte rupestre. La localidad de Ampajango, al sur de Andalhuala, es un lugar en el que los antiguos habitantes eligieron representar de manera profusa sus creencias con decenas de piedras grabadas (Fiore 1997; Lorandi 1966). Los bloques grabados encontrados en Andalhuala del Alto y del Bajo, emplazados sobre los glacis, entre 
los cuales se abre el paso hacia Ampajango, pudieron ser marcadores en el paisaje de los caminos a seguir durante peregrinajes a los campos de petroglifos del sur (Álvarez 2015).

Por su parte, el hallazgo de la Gruta de Chiquimí, en el bajo de la Mesada Alto de Andalhuala, nos permitió aproximarnos a una modalidad de arte rupestre que era desconocida para Yocavil (Álvarez, Cabrera y Carbonelli 2011). La presencia de grabados en un alero de areniscas marca la singularidad que ha tenido el ambiente de glacis en los modos de habitar de las poblaciones locales (figura 10). La situación de baja visibilidad de las representaciones indica que los grabados fueron elaborados por y para grupos que conocieron el lugar.

Figura 10. a. Acceso a la GCh desde las areniscas de Andalhuala (la flecha blanca indica el alero); b. vista de la GCh hacia el sur, las líneas punteadas indican el sector con grabados; c. vista desde la GCh hacia el norte de la quebrada.

Por otro lado, la localización de los grabados en el entorno de la montaña puede ser entendida en el marco del culto a los cerros en el mundo andino. Los cerros y las montañas son protagonistas indiscutibles de los paisajes andinos e influyen en la cosmovisión de los grupos que los habitaron (Gil y Fernández 2008). Los cerros son lugares de origen mitológico, centros de peregrinación y espacios rituales donde se localizan entidades tutelares. Como puntos sagrados del paisaje con cualidad de trascender en el tiempo debido a su carácter imperecedero, los cerros se constituyen en lugares de adoración y son escenarios del ritual para el pago de ofrendas (Aschero, Martel y López 2009; Gallardo, Sinclaire y Silva 1999). Este protagonismo de los cerros en la cosmovisión andina se encuentra estrechamente vinculado a su importancia económica. De los cerros, entidades masculinas, desciende un recurso vital para la vida como es el agua que fecunda la tierra (Aschero, Martel y López 2009; Gil y Fernández 2008), de ahí la relevancia que pudo tener la localización de los grabados a la vera de un cauce que en época estival descarga agua de lluvia y deshielo. Refuerza esta interpretación la presencia de motivos (líneas en zigzag, serpiente, tridígitos y antropomorfo femenino), que pudieron tratar el tema de la importancia del agua y la fertilidad de la tierra. Así, la gruta pudo funcionar como un geosigno en el paisaje (Álvarez 2012), no solo expresando creencias, sino también marcando el lugar donde hacer el pedido o pago a las entidades tutelares de la montaña para garantizar buenas cosechas y la reproducción de los animales en el marco de rituales productivos. 


\section{Incas y españoles a la conquista de los valles Calchaquíes (1430-1665 d. C.)}

Para inicios del siglo XV d. C., al parecer el NOA ya formaba parte del Kollasuyu, la provincia sur del Imperio incaico (Greco 2012; Marsh et al. 2017). La ocupación inca en esta región fue intensa pero selectiva, con algunos asentamientos imperiales y numerosos sectores intrusivos en sitios locales; por su parte, muchos pukaras disminuyen en intensidad de uso. En el Kollasuyu, la provincia de Quire-Quire (sur del valle Calchaquí, Yocavil, Andalgalá, Hualfín y Abaucán) fue fuente de producción agropecuaria, riquezas minerales y artesanos metalúrgicos especializados (D’Altroy, Williams y Lorandi 2007).

La variabilidad en el modo de ocupación incaica sugiere que se habrían utilizado una serie de estrategias desde la negociación hasta el enfrentamiento armado. Al parecer, la resistencia de los “diaguitas” obligó a implementar medidas más severas, como el destierro de ciertos grupos y la implantación de mitmaqkuna (colonos), procesos que comenzaron a alterar el mapa étnico de la zona (Lorandi 1988, 2000; Williams 2003).

En los valles Calchaquí y Yocavil, los incas construyeron su paisaje con base en la instalación de centros estatales en áreas estratégicas ( $v$. gr. Cortaderas, Potrero de Payogasta, Angastaco o Punta de Balasto), la remodelación de sectores arquitectónicos en poblados locales (La Paya, Tolombón, Quilmes, Fuerte Quemado, El Pichao o Ampajango), la intensificación de la producción agrícola con la construcción de andenes, canales y sistemas de almacenamiento (Mayuco, Corralito, Hualfín) y la construcción de fortalezas fronterizas y santuarios de altura (Pucará de Aconquija, Nevado de Chuscha, Cerro Galán) (Tarragó y González 2005; Williams y Castellanos 2011).

En el momento no hay en Andalhuala evidencias incaicas significativas. Una unidad emplazada en la Mesada de Andalhuala Banda, con dos recintos de clara modalidad tardía, presenta un cerramiento mayor. Este patrón de un gran patio con habitaciones de planta cuadrangular adosados al interior se corresponde con el diseño de la kancha incaica o rectángulo perimetral compuesto (RPC), como ha sido denominado para el NOA. La instalación de los RPC ha sido registrada en asociación con importantes poblados preexistentes (Raffino 2007). La remodelación de Loma Rica de Shiquimil, en momentos incaicos, que le otorgó una plaza trapezoidal (González y Tarragó 2005), pudo implicar también la construcción de un RPC en su proximidad. Tal vez los administradores estatales establecieron relaciones diplomáticas con los líderes locales, sin influir de manera profunda en sus aspectos organizativos internos. 
Unos 50 años después de la conquista incaica del NOA, los españoles ya se encontraban en tierras americanas y el Imperio incaico se desintegró. Con la llegada de Diego de Almagro desde Perú, en 1536, comenzó progresivamente, pero no sin conflictos y enfrentamientos bélicos (Lorandi 2000; Palomeque 2000), la ocupación española de los valles, que dio inicio al llamado periodo HispanoIndígena (Stenborg 2003; Tarragó 1984) o, más recientemente, Colonial Temprano (1536-1665) (Marchegiani 2011) ${ }^{9}$, etapa histórica en que los indígenas de los valles permanecieron en estado de guerra con los colonos y que ha sido más abordada desde la etnohistoria que desde la arqueología. Durante el siglo XVI, el valle de Yocavil fue un lugar de tránsito de los ejércitos españoles. La penetración española constituyó una conquista diferente a la incaica, realizada por hombres con una cultura radicalmente disímil, otra lengua y, sobre todo, ajenos a los modos de vida andinos que se habían ido desarrollando a partir de un conocimiento profundo del paisaje. Los conquistadores, en su mayoría españoles marginados en su propia sociedad, sojuzgaron a las poblaciones nativas con el anhelo de nuevas tierras y riquezas. La introducción de especies vegetales, la expansión de la ganadería europea y la obligación de prestar servicios y pagar tributos alteró los patrones de asentamiento y los sistemas productivos indígenas.

Los primeros años de ocupación española en el valle fueron de carácter defensivo, mediante fundaciones en lugares estratégicos para el paso de las huestes reales (Meister, Petruzzi y Sonzogni 1963). De a poco, se fue implantando una sociedad señorial en la que las poblaciones locales fueron sometidas a partir de encomiendas y repartimientos; los indígenas pasaron a ser propiedad de los señores españoles, y debieron pagar impuestos y prestar servicios, algunos rayanos en la esclavitud. Al avance de la conquista militar del territorio lo acompañó la evangelización de las almas por jesuitas y franciscanos.

Los abusos sufridos por las poblaciones del valle, y su carácter aguerrido, llevaron a numerosas sublevaciones a lo largo de 130 años, una resistencia singular en el mundo andino conocida en la historiografía local como las Guerras Calchaquíes, cuando los indígenas ataviados con arcos y flechas desde sus fortalezas en los cerros pusieron en jaque el asentamiento español (Boixadós 2011; Lorandi 2000; Palomeque 2000; Rodríguez 2008; Tarragó 1984). Estas sociedades contaban con una organización social multiétnica y fragmentaria, dispuesta a confederarse para resistir de manera conjunta los embates de los conquistadores

$9 \quad$ El concepto colonial temprano busca resaltar que las sociedades locales fueron participantes activas en las transformaciones socioeconómicas y culturales que experimentaron durante la Conquista y no meras receptoras pasivas de los cambios impuestos por los europeos (Marchegiani 2011, 246-248). 
a través de alianzas entre grupos locales al mando de líderes carismáticos como Juan Calchaquí, cacique de Tolombón (Lorandi 2000; Rodríguez 2011; Williams 2003). Entre los años 1534 y 1565, Juan Calchaquí y sus aliados arrasaron varias ciudades españolas. Entre 1565 y 1593, fueron fundadas las ciudades de San Miguel de Tucumán, Córdoba, Salta, La Rioja y Jujuy, que conformaron un cerco sobre las poblaciones indígenas del valle Calchaquí que permanecían rebeldes. Entre 1630 y 1643, se desencadenó el "gran alzamiento" liderado por Chalemín, cacique malfín de Andalgalá, y que involucró una parte importante de las poblaciones de los valles y quebradas del NOA. Según cuentan las crónicas, Utimpa, cacique de los yocaviles, fue uno de los principales líderes rebeldes que combatió bajo el mando de Chalemín. Para 1657, este pueblo contaba con 500 "indios de pelea” y 2.500 "almas de familia” (Boixadós 2011). El tercer Alzamiento Calchaquí se dio entre 1656 y 1665, cuando Pedro Bohórquez, un español autoproclamado último descendiente del Inca, lideró un alzamiento general. Las rebeliones fueron finalmente sofocadas entre 1659 y 1666 por el gobernador del Tucumán, Alonso de Mercado y Villacorta. Incontables indígenas perdieron la vida y grupos enteros fueron desnaturalizados ${ }^{10}$, como el conocido caso de los quilmes, obligados a caminar hasta la provincia de Buenos Aires. En el sur de Yocavil, yocaviles, tucumangastas e ingamanas fueron repartidos en encomiendas por familias nucleares en distintos parajes de La Rioja y Catamarca (Boixadós 2011; Rodríguez 2008).

No contamos aún con evidencias arqueológicas sobre los paisajes de Andalhuala en estos momentos. El destierro de los yocaviles probablemente implicó un abandono masivo de los asentamientos o, al menos, una reducción considerable con un cambio en los patrones de uso del espacio y las viviendas, como ha sido registrado en otros sectores del valle (Stenborg 2003), hipótesis que deberá ser contrastada con excavaciones arqueológicas que se concentren en dicho periodo.

Las desnaturalizaciones resolvieron dos problemas para la empresa española: la liberación de las tierras del valle para ser explotadas por los colonos y la disponibilidad de mano de obra indígena. Las mercedes -el reparto de las tierras nativas por parte del rey de España a sus vasallos en América- y las encomiendas - la entrega de nativos a los españoles para trabajar en sus haciendas-dieron inicio a una nueva etapa en el devenir de los paisajes del valle. 


\section{La sociedad colonial y el repoblamiento indígena de los valles (siglos XVII-XVIII)}

La finalización de las Guerras Calchaquíes constituyó un verdadero punto de inflexión en la historia del valle; hacia fines del siglo XVII y comienzos del siglo XVIII, la sociedad colonial se afianzó a partir de la instalación permanente de religiosos, la construcción de templos y pueblos y la repartición de tierras y encomiendas (Tarragó 1984).

A comienzos del siglo XVII, una disposición de la Corona determinó que toda la población indígena sujeta a encomiendas debía convivir nucleada en asentamientos fijos, los llamados "pueblos de indios", para facilitar su control, evangelización y pago de tributo (López 2006; Palomeque 2000). La porción sur del valle de Yocavil fue una excepción dado que allí no se establecieron pueblos de indios luego de las Guerras Calchaquíes; los indígenas que sobrevivieron pasaron a formar parte del sistema de encomiendas de servicio personal, viviendo en las haciendas de los españoles y desmembrados de sus comunidades, lo cual implicaba que ya no poseyeran tierras comunales para su usufructo. Los colalaos, tolombones y amaichas fueron de los pocos grupos que lograron mantener sus tierras, así como su sistema de autoridades, mientras que el resto de los indígenas calchaquíes llegaron a fines de la Colonia sin tierras ni pueblos (Palomeque 2000). Según ha podido reconstruir Lorena Rodríguez (2008), el proceso de reasignación de tierras en Yocavil se inició a fines de la década de 1660 por la zona de Punta de Balasto (localidad más austral del valle). Este proceso no fue sencillo y suscitó varios conflictos debido a superposiciones de mercedes de tierras y artilugios de diversos actores.

Para fines del siglo XVII, con el efectivo control español, el uso y la organización social del espacio del valle se modificó con respecto a los patrones de asentamiento prehispánicos; la ocupación española privilegió el fondo de valle (más apto para el traslado a caballo y con mejores tierras para cultivos), y adquirió de a poco las características que perduran hasta la actualidad. Las antiguas fortificaciones militares y misiones evangelizadoras fueron el origen de los nuevos centros urbanos como Santa María, que para esta época consistía en un caserío donde unas pocas familias españolas convivían con indígenas que les pertenecían.

El cambio de estructura en el uso del paisaje se concreta en el siglo XVIII, cuando cobran mayor importancia las poblaciones asentadas en el centro del valle en desmedro de los caseríos ubicados en las quebradas transversales. Desde 
la instalación del modelo español de uso de la tierra, el valle Calchaquí y el norte de Yocavil se constituyeron como una zona latifundista que se fue configurando como una próspera región productora de vinos; el sur, por su parte, se constituyó en una zona minifundista de propietarios criollos. Hacia fines del siglo XVIII, la reactivación económica del centro minero de Potosí consolidó al espacio sur andino como eje de un importante comercio mular, siendo los valles de Lerma y Calchaquí los principales lugares de invernada. La mortalidad indígena facilitó el auge ganadero en tanto la reducción de la población y el abandono de los campos de cultivo dejaron las tierras libres para la expansión ganadera (Palomeque 2000).

Sin embargo, las investigaciones de Rodríguez $(2008,2011)$ han permitido poner en tela de juicio la idea de la desaparición de los indígenas del valle producto de las desnaturalizaciones y su configuración como un espacio netamente mestizo, pues hacia mediados del siglo XVII, las autoridades españolas se mostraban aún preocupadas por el regreso de los pobladores nativos. A estas huidas voluntarias de regreso al valle se sumaban los nuevos traslados de los indígenas por parte de los españoles para que trabajaran en sus propiedades.

A fines del siglo XVIII se registra un incremento de la población en Yocavil, debido a la llegada de nuevos españoles (que aún constituían una minoría), y de poblaciones indígenas de distintos orígenes (principalmente de Atacama y el Alto Perú, así como indígenas mocovíes y tobas traídos a la fuerza). Así, las rebeliones, las muertes (por epidemias o conflictos armados), las desnaturalizaciones, el proceso de mestizaje, las encomiendas y la llegada de indígenas provenientes de otras zonas alteraron la constitución de los grupos nativos y sus rasgos identitarios originarios.

El siglo XVIII implicó nuevos desafíos para las poblaciones nativas sobrevivientes; las reformas borbónicas implementadas por la Corona a partir de la década de 1770 pusieron fin al sistema de encomiendas y servicios personales (del que solo se beneficiaba el encomendero) y establecieron un nuevo tipo de tributo anual que se debía pagar, tanto por originarios como por forasteros, directamente a la Corona - proceso lento en Santa María, donde hasta fines de siglo aún existían indígenas en encomiendas privadas- (Rodríguez 2008).

La sociedad santamariana a fines del siglo XVII absorbió buena parte de los mestizos bajo la categoría de “españoles”, situación que cambió a finales del siglo XVIII, cuando la sociedad se volvió más rígida y jerarquizada. Esta se caracterizó por ser muy estratificada, y los españoles peninsulares y criollos conformaron la cúspide de la pirámide social. La sociedad se aglutinaba alrededor de la familia española con propiedad de la tierra expropiada a los nativos, integrada 
por indígenas y negros asignados al servicio personal, quienes portaban el apellido familiar como signo de posesión.

El actual pueblo de Andalhuala se fue configurando hacia finales del siglo XVIII, cuando personas asentadas en la zona comenzaron a comprar tierras dadas sus buenas condiciones para el cultivo y la ganadería. Para entonces, ya se cultivaba nuez, durazno, membrillos y uvas y se criaba ganado bovino, caprino y vacuno. Según Meister, Petruzzi y Sonzogni (1963), la conformación del minifundio en esta zona pudo deberse a que los propietarios fueron subdividiendo las haciendas para otorgárselas como herencia a sus hijos. Según Rodríguez (2008), es necesario señalar que ya de por sí en el sur de Yocavil las tierras otorgadas en merced o las compradas nunca alcanzaron grandes extensiones, con la excepción de la estancia San Juan de Ingamana de la familia Retamoso. Estas características tempranas de la ocupación de Andalhuala la configuraron como una zona de pequeños productores agropecuarios, situación que se mantiene hasta la actualidad ${ }^{11}$.

\section{Consideraciones finales}

Como mencionamos al inicio de este trabajo, en el actual contexto de revalorización de rasgos de las culturas ancestrales en Argentina, en general, y en el noroeste del país, en particular, este artículo se propuso como objetivo realizar una síntesis del devenir histórico de los paisajes de Andalhuala, tomando como eje articulador el estudio de los paisajes culturales, entendidos como construcciones sociales que son el producto de la interacción de las personas con sus entornos. El caso de estudio presentado nos permitió entender los procesos de cambio en el largo plazo que han tenido los paisajes precolombinos del noroeste argentino, en relación con los diversos modos de habitar de las poblaciones nativas y foráneas, los sucesivos episodios de conquista (Imperio inca e Imperio español) y la consecuente configuración de nuevas identidades sociales.

11 Hoy, Andalhuala sufre un proceso importante de despoblamiento, con la venta o el abandono de las fincas, debido a los altos costos de mantenimiento (abonos, pesticidas, años de mala producción, etc.), la escasez de mano de obra y los bajos precios de la demanda (principalmente de la nuez, que es el producto más comercializado). Según el censo de 1991, la población de Andalhuala era de 321 habitantes, número que fluctuó ligeramente en las décadas siguientes (339, según el censo del 2001, y 284, según el del 2010). 
A partir de una revisión de la información disponible, producto de estudios arqueológicos, histórico-antropológicos y etnohistóricos, buscamos narrar la historia de Andalhuala a través de grandes bloques temporales, desde los primeros grupos cazadores-recolectores que habitaron la zona hasta el periodo Colonial Tardío, momento en que se afianza la sociedad española, al tiempo que se produce un proceso de repoblamiento indígena en los valles. En este proceso tratamos de reconstruir la larga secuencia de ocupación prehispánica que tuvo la localidad, y cómo los modos de habitar de los distintos pueblos fueron configurando un palimpsesto de paisajes en los que se perdieron, modificaron o resignificaron materialidades de paisajes previos.

La revisión de la información generada por otros equipos y por nosotros mismos nos ha permitido notar la disparidad, tanto en cantidad como en calidad, de la información disponible en lo que respecta al desarrollo de Andalhuala y la necesidad de avanzar desde el análisis de documentos y desde la arqueología en el estudio de ciertos momentos históricos particulares, como los periodos Colonial Temprano y Colonial Tardío.

Actualmente, la mayoría de los pobladores de Andalhuala consideran el legado arqueológico de la zona como perteneciente al pasado prehispánico de sus antiguos habitantes sin vínculos directos con ellos; no obstante, muestran un interés genuino por conocerlo e incorporarlo a su herencia cultural. Esperamos que este trabajo contribuya en el camino de satisfacer ese deseo y permita ir recuperando la memoria de las poblaciones nativas que allí habitaron.

\section{Agradecimientos}

A los pobladores de Andalhuala por su siempre cordial recibimiento. A todos los miembros del equipo Yocavil que han participado en distintos trabajos de campo en la zona y han contribuido a la generación de conocimiento sobre Andalhuala. En especial, a Romina Spano por su lectura de una versión temprana de este manuscrito. A los evaluadores anónimos y editores cuyos comentarios mejoraron significativamente el presente escrito. Este trabajo fue posible gracias a una beca posdoctoral otorgada por la Universidad Nacional Autónoma de México a través de la Dirección General de Asuntos del Personal Académico (DGAPA). 


\section{Referencias}

Albeck, María Ester. 2000. "La vida agraria en los Andes del Sur". En Nueva historia argentina I. Los pueblos originarios y la Conquista, editado por Myriam N. Tarragó, 187-228. Buenos Aires: Sudamericana.

Álvarez Larrain, Alina. 2010. “Arquitectura y paisajes en la localidad arqueológica de Andalhuala (valle de Yocavil, Catamarca)”. Revista del Museo de Antropología 3: 33-48.

—. 2012. "El arte rupestre como geosigno del paisaje (valle de Yocavil, Catamarca, Argentina)”. Comechingonia, Revista de Arqueología 16 (2): 55-74.

-. 2015. "Habitar una región. Espacialidad arquitectónica y construcción de paisajes en Andalhuala, valle de Yocavil (Catamarca, Argentina)". Tesis doctoral en Arqueología, Facultad de Filosofía y Letras, Universidad de Buenos Aires.

-. 2016a. "Don Mateo-El Cerro, a Newly Rediscovered Late Period Settlement in Yocavil (Catamarca, Argentina)”. Andean Past 12: 203-210.

-. 2016b. "Paisajes agroalfareros del primer y segundo milenio DC en la Terraza de Andalhuala Banda (Yocavil, noroeste argentino)”. Ñawpa Pacha. Journal of Andean Archaeology 36 (2): 161-184.

Álvarez Larrain, Alina, Fernando Cabrera y Juan Pablo Carbonelli. 2011. "Gran Gruta Grabada de Chiquimí. Noticia acerca de su hallazgo y redescubrimiento, 100 años después”. Boletín del Museo Chileno de Arte Precolombino 16 (1): 23-46.

Álvarez Larrain, Alina, Romina Spano y María Solange Grimoldi. En prensa. "Ollas como urnas, casas como tumbas: reflexiones en torno a las prácticas de entierro de niños en tiempos tempranos (Andalhuala Banda, sur de Yocavil)”. Comechingonia, Revista de Arqueología.

Ambrosetti, Juan Bautista. 1899. “Notas de arqueología calchaquí (continuación)”. Boletín del Instituto Geográfico Argentino 20: 253-302.

Anschuetz, Kurt F., Richard H. Wilshusen y Cherie L. Scheick. 2001. "An Archaeology of Landscapes: Perspectives and Directions”. Journal of Archaeological Research 9 (2): 152-197.

Arkush, Elizabeth. 2011. Hillforts of the Ancient Andes. Colla Warfare, Society and Landscape. Gainesville: University Press of Florida.

Arkush, Elizabeth y Charles Stanish. 2005. "Interpreting Conflict in the Ancient Andes. Implications for the Archaeology of Warfare”. Current Anthropology 46 (1): 3-27.

Arocena, María Luisa y Blanca Carnevali. 1960. “Andalhuala”. En Investigaciones arqueológicas en el Valle de Santa María, 53-63. Rosario: Instituto de Antropología, Facultad de Filosofía y Letras, Universidad Nacional del Litoral.

Aschero, Carlos. 2000. "El poblamiento del territorio”. En Nueva historia argentina I. Los pueblos originarios y la Conquista, editado por Myriam Noemí Tarragó, 17-59. Buenos Aires: Sudamericana.

Aschero, Carlos, Álvaro Martel y Sara López Campeny. 2009. "El sonido del agua... Arte rupestre y actividades productivas. El caso de Antofagasta de la Sierra, noroeste argentino”. 
En Crónicas sobre la piedra. Arte rupestre de las Américas, editado por Marcela Sepúlveda Retama, Juan Chacama Rodríguez y Luis Briones Morales, 257-270. Arica: Universidad de Tarapacá.

Baigorria di Scala, Jennifer. 2009. "El sitio Formativo Soria 2: estudio tecnomorfológico del conjunto cerámico ordinario”. Tesis de licenciatura, Facultad de Filosofía y Letras, Universidad de Buenos Aires.

Bailey, Geoff. 2007. “Time Perspectives, Palimpsests and the Archaeology of Time”. Journal of Anthropological Archaeology 26: 198-223.

Bender, Barbara. 1993. Landscape: Politics and Perspectives. Oxford: Berg.

Berberián, Eduardo y Axel Nielsen. 1988. "Sistemas de asentamiento prehispánicos en la etapa formativa del valle de Tafí (Pcia. de Tucumán-República Argentina)”. En Sistemas de asentamiento prehispánicos en el valle de Tafí, editado por Eduardo Berberián, 21-51. Córdoba: Comechingonia.

Boixadós, Roxana. 2011. "El fin de las Guerras Calchaquíes. La desnaturalización de la nación yocavil a La Rioja (1667)”. Corpus. Archivos Virtuales de la Alteridad Americana 1 (1). Consultado el $1 .^{\circ}$ de septiembre del 2016. http://ppct.caicyt.gov.ar/index.php/corpus.

Bolsi, Alfredo Segundo. 1967. Estudio antropogeográfico del Valle de Santa María-Catamarca. Resistencia: Publicaciones del Departamento de Extensión Universitaria y Ampliación de Estudios, Universidad Nacional del Nordeste.

Bonnin, Marta y Andrés Laggens. 2000. "Esteros y algarrobales. Las sociedades de las sierras centrales y la llanura santiagueña”. En Nueva historia argentina I. Los pueblos originarios y la Conquista, editado por Myriam Noemí Tarragó, 147-186. Buenos Aires: Sudamericana.

Bourdieu, Pierre. (1972) 2012. Bosquejo de una teoría de la práctica. Buenos Aires: Prometeo.

Bouysse-Cassagne, Thérése y Olivia Harris. 1987. "Pacha: en torno al pensamiento aymara”. En Tres reflexiones sobre el pensamiento andino, editado por Thérése Bouysse-Cassagne, Olivia Harris, Tristan Platt y Verónca Cereceda, 11-59. La Paz: Hisbol.

Cabrera, Ángel. 1976. “Regiones fitogeográficas argentinas”. En Enciclopedia argentina de agricultura y jardinería II, editado por Walter Federico Kugler, 1-85. Buenos Aires: Acme.

Carbonelli, Juan Pablo. 2011. “'Motivos por qué y para’ en la tecnología lítica de un sitio formativo en el valle de Yocavil, provincia de Catamarca”. Intersecciones en Antropología 12: $31-45$.

—. 2013a. "Técnicas líticas en paisajes cazadores y agropastoriles al sur del valle de Yocavil”. Tesis doctoral, Facultad de Filosofía y Letras, Universidad de Buenos Aires.

—. 2013b. “El sitio Ampajango. Cincuenta años después”. Arqueología 19 (1): 41-64.

Castro, Victoria y Myriam Noemí Tarragó. 1992. "Los inicios de la producción de alimentos en el Cono Sur de América”. Revista de Arqueología Americana 6: 91-124.

Censo Nacional de Población y Vivienda. 1991. Buenos Aires: Instituto Nacional de Estadística y Censos.

Censo Nacional de Población, Hogares y Viviendas. 2001. Buenos Aires: Instituto Nacional de Estadística y Censos. 
Censo Nacional de Población, Hogares y Viviendas. 2010. Buenos Aires: Instituto Nacional de Estadística y Censos.

Cigliano, Eduardo Mario, Susana Bereterbide, Blanca Carnevali, Ana M. Lorandi y Myriam Tarragó. 1962. El ampajanguense. Rosario: Instituto de Antropología, UNL.

Criado Boado, Felipe. 1999. "Del terreno al espacio: planteamientos y perspectivas para la arqueología del paisaje”. CAPA 6: 1-58.

D’Altroy, Terence, Verónica Williams y Ana María Lorandi. 2007. "The Inkas in the Southlands”. En Variations in the Expression of Inka Power, editado por Richard Burger, Craig Morris y Ramiro Matos, 85-133. Washington DC: Dumbarton Oaks.

Fiore, Danae. 1997. "Analysis of Ampajango Rock Art, Santa María, Argentina: An Approach to the Structure of its Designs and the Technology of its Production”. Tesis de maestría, Institute of Archaeology, University of London.

Flores Ochoa, Jorge. 1977. "Pastoreo, tejido e intercambio". En Pastores de puna = uywamichiq punarunakuna, editado por Jorge Flores Ochoa, 133-154. Lima: Instituto de Estudios Peruanos.

Gallardo, Francisco, Carola Sinclaire y Claudia Silva. 1999. "Arte rupestre, emplazamiento y paisaje en la cordillera del desierto de Atacama”. En Arte rupestre en los Andes de Capricornio, editado por José Berenguer y Francisco Gallardo, 57-96. Santiago de Chile: Museo Chileno de Arte Precolombino.

Gil García, Francisco y Gerardo Fernández Juárez. 2008. "El culto a los cerros en el mundo andino”. Revista Española de Antropología Americana 38 (1): 105-113.

Giudicelli, Christophe. 2013. "Hablar la lengua del enemigo: la soledad del misionero en tierras calchaquíes”. Revista Tempo 19 (35): 1-22.

González, Alberto. 1952. "Antiguo horizonte precerámico en las Sierras Centrales de Argentina”. Runa 5: 110-113.

-. 1960. "La estratigrafía de la gruta de Intihuasi (prov. de San Luis, R. A.) y sus relaciones con otros sitios precerámicos de Sudamérica”. Revista del Instituto de Antropología I: 5-296.

—. 1977. Arte precolombino de la Argentina. Buenos Aires: Filmediciones Valero.

González, Luis y Myriam Noemí Tarragó. 2005. “Vientos del sur. El valle de Yocavil (noroeste argentino) bajo la dominación incaica”. Estudios Atacameños 29: 67-95.

González Dubox, Raúl, Federico Wynveldt, Valentín Val y Manuel López Mateo. 2011. "Análisis espacial del Cerrito Colorado de la Ciénaga de Arriba (departamento de Belén, Catamarca)”. La Zaranda de Ideas 7: 23-48.

Greco, Catriel. 2012. "Integración de datos arqueológicos, radiocarbónicos y geofísicos para la construcción de una cronología de Yocavil y alrededores”. Tesis doctoral, Facultad de Filosofía y Letras, Universidad de Buenos Aires.

Ingold, Tim. 2000. The Perception of the Environment. Londres: Routledge.

Isla, Alejandro. 2003. "Los usos políticos de la memoria y la identidad”. Estudios Atacameños 26: $35-44$. 
Korstanje, María Alejandra, Marisa Lazzari, Mara Basile, Fabiana Bugliani, Verónica Lema, Lucas Pereyra Domingorena y Marcos Quesada, eds. 2015. Crónicas materiales precolombinas. Arqueología de los primeros poblados del noroeste argentino. Buenos Aires: Sociedad Argentina de Antropología.

Lafone Quevedo, Samuel. 1898. Tesoro de catamarqueñismos. Nombres de lugar y apellidos indios con etimologías y eslabones aislados de la lengua cacana. Buenos Aires: Coni e Hijos.

Lazzari, Marisa y María Alejandra Korstanje. 2013. "The Past as a Lived Space: Heritage Places, Re-emergent Aesthetics, and Hopeful Practices in NW Argentina”. Journal of Social Archaeology 3 (13): 394-419.

López, Cristina. 2006. “Tierras comunales, tierras fiscales: el tránsito del orden colonial a la revolución”. En La propiedad de la tierra. Pasado y presente. Estudios de arqueología, historia y antropología sobre la propiedad de la tierra en la Argentina, compilado por Enrique Cruz y Rosana Paolini, 39-67. Anuario del CEIC/3. Córdoba: Alción Editora.

Lorandi, Ana María. 1966. "El arte rupestre del noroeste argentino. Área del norte de La Rioja y sur y centro de Catamarca”. Dédalo 2 (4): 15-172.

-. 1988. "Los diaguitas y el Tawantinsuyu: una hipótesis de conflicto". En La frontera del Estado inca, editado por Tom Dillehay y Patricia Netherly, 215-234. Oxford: BAR Internacional Series 442 .

-. 2000. "Las rebeliones indígenas”. En Nueva historia argentina: la sociedad colonial II, editado por Enrique Tandeter, 285-330. Buenos Aires: Sudamericana.

Lorandi, Ana María y Roxana Boixadós. 1987-1988. "Etnohistoria de los Valles Calchaquíes en los siglos XVI y XVII”. Runa XVII-XVIII: 263-420.

Lorandi, Ana María, Roxana Boixadós, Cora Bunster y Miguel Ángel Palermo. 1997. "El Valle Calchaquí”. En El Tucumán colonial y Charcas I, compilado por Ana María Lorandi, 205-251. Buenos Aires: Facultad de Filosofía y Letras, Universidad de Buenos Aires.

Marchegiani, Marina. 2011. "Las formaciones sociales de Yocavil durante la dominación inca y la Conquista española. Contacto, conflicto, persistencia y transformaciones (siglos XV-XVII d. C.)”. Tesis doctoral, Facultad de Filosofía y Letras, Universidad de Buenos Aires.

Marchegiani, Marina, Valeria Palamarczuk, Gerónimo Pratolongo y Alejandra Reynoso. 2006. "Nunca serán ruinas: visiones y prácticas en torno al antiguo poblado de Quilmes en Yocavil”. En Problemáticas en la arqueología contemporánea I, coordinado por Antonio Austral y Marcela Tamagnini, 313-323. Río Cuarto: Universidad Nacional de Río Cuarto.

Marsh Erik, Ray Kidd, Dennis Ogburn y Víctor Durán. 2017. "Dating the Expansion of the Inca Empire: Bayesian Models from Ecuador and Argentina”. Radiocarbon 59 (1): 117-140.

Meister, Albert, Susana Petruzzi y Elida Sonzogni. 1963. Tradicionalismo y cambio social. Estudio de área en el valle de Santa María. Rosario: Facultad de Filosofía y Letras, Universidad Nacional del Litoral.

Miller, Daniel, ed. 2005. Materiality. Durham: Duke University Press.

Nielsen, Axel. 2001. “Evolución social en Quebrada de Humahuaca (AD 700-1536)”. En Historia argentina prehispánica I, editado por Eduardo Berberián y Axel Nielsen, 171-264. Córdoba: Brujas. 
-. 2007. "Armas significantes: tramas culturales, guerra y cambio social en el sur andino prehispánico”. Boletín del Museo Chileno de Arte Precolombino 12 (1): 9-41.

-. 2009. "Ancestors at War. Meaningful Conflict and Social Process in the South Andes". En Warfare in Cultural Context, editado por Axel Nielsen y William Walker, 218-242. Tucson: The University of Arizona Press.

Olivera, Daniel. 2001. "Sociedades agropastoriles tempranas: el Formativo Inferior del Noroeste Argentino”. En Historia argentina prehispánica I, editado por Eduardo Berberián y Axel Nielsen, 83-121. Córdoba: Brujas.

Palamarczuk, Valeria, Alina Álvarez Larrain y Solange Grimoldi. 2014. "La alfarería de inicios del segundo milenio en Yocavil. El problema 'San José’ y las tipologías cerámicas”. Revista Arqueología XX (dosier): 107-134.

Palamarczuk, Valeria, Romina Spano, Daniel Magnífico, Florencia Weber, Soledad López y Mariano Manasiewicz. 2007. "Soria 2. Apuntes sobre un sitio temprano en el valle de Yocavil (Catamarca, Argentina)”. Intersecciones en Antropología 8: 121-134.

Palomeque, Silvia. 2000. "El mundo indígena. Siglos XVI-XVIII”. En Nueva historia argentina: la sociedad colonial II, editado por Enrique Tandeter, 87-144. Buenos Aires: Sudamericana.

Podestá, Clara y Elena Perrotta. 1973. "Relaciones entre culturas del noroeste argentino. San José y Santa María”. Antiquitas 17: 6-15.

Raffino, Rodolfo. 2007. Poblaciones indígenas en Argentina. Buenos Aires: TEA.

Rodríguez, Lorena. 2008. Después de las desnaturalizaciones: transformaciones socioeconómicas y étnicas al sur del valle Calchaquí. Santa María, fines del siglo XVII-fines del siglo XVIII. Buenos Aires: Antropofagia.

- comp. 2011. Resistencias, conflictos y negociaciones. El valle Calchaquí desde el periodo prehispánico hasta la actualidad. Rosario: Prohistoria.

Rodríguez, Lorena y Ana María Lorandi. 2005. "Apropiaciones y usos del pasado. Historia y patrimonio en el valle Calchaquí”. Bulletin de l'Institut Francais d'Études Andines 34 (3): 431-442.

Rosso, Cintia y Romina Spano. 2005-2006. "Evidencias del uso de alucinógenos en pipas halladas en dos sitios tempranos de los valles Calchaquíes”. Arqueología 13: 79-98.

Ruiz, Marta. 1995-1996. "Prehistoria y arqueología regional: el noroeste argentino”. AnMurcia 11-12: 163-173.

Ruiz Huidobro, Osvaldo. 1972. “Descripción geológica de la hoja 11e, Santa María”. Boletín n. ${ }^{\circ}$ 134. Ministerio de Industria y Minería, Subsecretaría de Minería, Servicio Nacional Minero Geológico, Buenos Aires.

Scattolin, María Cristina. 2000. "Santa María durante el Primer Milenio A. D. ¿Tierra baldía?”. Etnografiska Museet i Goteborg Arstryck: 63-83.

—. 2010. "La organización del hábitat precalchaquí (500 a. C.-1000 d. C.)”. En El hábitat prehispánico. Arqueología de la arquitectura y de la construcción del espacio organizado, editado por María Esther Albeck, María Cristina Scattolin y Alejandra Korstanje, 13-51. San Salvador de Jujuy: FHyCS, UNJu. 
Smith, Adam. 2003. The Political Landscape. Constellations of Authority in Early Complex Polities. Berkeley: University of California Press.

Somonte, Carolina. 2009. "Tecnología lítica en espacios persistentes de Amaicha del Valle (Tucumán)”. Tesis doctoral, Facultad de Filosofía y Letras, Universidad de Buenos Aires.

Spano, Romina, Solange Grimoldi y Valeria Palamarczuk. 2014. "Morir temprano. Entierros de infantes en un espacio doméstico formativo de Yocavil, noroeste argentino”. Estudios. Antropología-Historia (nueva serie) 2: 141-173.

Stenborg, Per. 2003. "Buscando la sombra de Europa: investigaciones sobre el periodo Hispano-Indígena en el valle de Santa María”. En Local, regional, global: prehistoria, protohistoria e historia en los valles Calchaquíes, editado por Per Cornell y Per Stenborg, 287-299. Anales Nueva Época n. ${ }^{\circ}$ 6. Göteborg: Instituto Iberoamericano, Universidad de Göteborg.

Tarragó, Myriam. 1984. "El contrato hispano-indígena: la provincia de Chicoana”. Runa 14: 145-185.

-. 1999. "El Formativo y el surgimiento de la complejidad social en el noroeste argentino". En Formativo sudamericano, editado por Paulina Ledergerber-Crespo, 302-313. Quito: AbyaYala.

—. 2000. “Chacras y pukara: desarrollos sociales tardíos”. En Nueva historia argentina: los pueblos originarios y la Conquista I, editado por Myriam N. Tarragó, 257-300. Buenos Aires: Sudamericana.

-. 2011. "Poblados tipo pukara en Yocavil. El plano de Rincón Chico 1 (Catamarca, Argentina)”. Estudios Sociales del NOA 11: 33-61.

Tarragó, Myriam, Sergio Caviglia, Mercedes Peralta Sanhuesa y Jorge Sosa. 1988. "Los grupos cerámicos del poblado de Loma Rica de Shiquimil, Catamarca Argentina”. Ponencia presentada en el IX Congreso Nacional de Arqueología Argentina, Instituto de Ciencias Antropológicas, Buenos Aires, 31 de octubre al 5 de noviembre.

Tarragó, Myriam y Luis González. 2005. "Variabilidad en los modos arquitectónicos incaicos. Un caso de estudio en el valle de Yocavil (noroeste argentino)”. Chungará 37 (2): 129-143.

Tarragó, Myriam y María Cristina Scattolin. 1999. "La problemática del periodo Formativo en el valle de Santa María”. Actas del XII Congreso Nacional de Arqueología Argentina I: 142-153. La Plata.

Thiébaut, Virginia, Magdalena García Sánchez y María Antonieta Jiménez Izarraraz. 2008. Introducción a Patrimonio y paisajes culturales, editado por Virginia Thiébaut, Magdalena García Sánchez y María Antonieta Jiménez Izarraraz, 13-36. Zamora: El Colegio de Michoacán.

Thomas, Julian. 2001. “Archaeology of Place and Landscape”. En Archaeology Theory Today, editado por Ian Hodder, 165-186. Cambridge: Polity Press.

Tilley, Cristopher. 1994. A Phenomenology of Landscape. Place, Paths and Monuments. Oxford y Providence: Berg.

Tineo, Alfredo. 2005. Estudios hidrogeológicos del valle del río Santa María, provincia de Catamarca. Serie Correlación Geológica 20. San Miguel de Tucumán: Insugeo. 
Tuan, Yi-Fu. (1977) 2003. Space and Place. The Perspective of Experience. Minneapolis: University of Minnesota Press.

Uribe Rodríguez, Mauricio, Leonor Adán Alfaro y Carolina Agüero Piwonka. 2004. "Arqueología de los periodos Intermedio Tardío y Tardío de San Pedro de Atacama y su relación con la cuenca del río Loa”. Chungará 36 (supl. especial 2): 943-956.

Williams, Verónica. 2003. "Nuevos datos sobre la prehistoria local en la quebrada de Tolombón. Pcia. de Salta. Argentina”. En Local, regional, global: prehistoria, protohistoria e historia en los Valles Calchaquíes, editado por Per Cornell y Per Stenborg, 163-209. Anales Nueva Época n. ${ }^{\circ}$ 6. Göteborg: Instituto Iberoamericano, Universidad de Göteborg.

Williams, Verónica y María Cecilia Castellanos. 2011. "Poblaciones prehispánicas en las cuencas de Angastaco y Molinos. Historia de conflictos, resistencias y disputas”. En Resistencias, conflictos y negociaciones. El valle Calchaquí desde el periodo prehispánico hasta la actualidad, compilado por Lorena Rodríguez, 23-61. Rosario: Prohistoria.

Wynveldt, Federico. 2009. La Loma de los Antiguos de Azampay. Un sitio defensivo del Valle de Haulfín (Catamarca, Argentina). Buenos Aires: Sociedad Argentina de Antropología.

Yacobaccio, Hugo D. y Bibiana Vilá. 2012. "La domesticación de los camélidos andinos como proceso de interacción humana y animal”. Intersecciones en Antropología 14: 227-238.

Zedeño, María Nieves. 2000. "On What People Make of Places. A Behavioral Cartography”. En Social Theory in Archaeology, editado por Michael Schiffer, 97-111. Salt Lake City: University of Utah Press. 